\title{
Area-specific analysis of the distribution of hypothalamic neurons projecting to the rat ventral tegmental area, with special reference to the GABAergic and glutamatergic efferents
}

\author{
Imre Kalló ${ }^{1,2 *}$, Csilla S. Molnár ${ }^{1}$, Sarolta Szöke ${ }^{1}$, Csaba Fekete ${ }^{3,4}$, Erik Hrabovszky ${ }^{1}$ and \\ Zsolt Liposits ${ }^{1,2}$ \\ ${ }^{1}$ Laboratory of Endocrine Neurobiology, Institute of Experimental Medicine, Hungarian Academy of Sciences, Budapest, \\ Hungary, ${ }^{2}$ Faculty of Information Technology and Bionics, Pázmány Péter Catholic University, Budapest, Hungary, \\ ${ }^{3}$ Laboratory of Integrative Neuroendocrinology, Institute of Experimental Medicine, Hungarian Academy of Sciences, \\ Budapest, Hungary, ${ }^{4}$ Department of Medicine, Division of Endocrinology, Diabetes and Metabolism, Tupper Research \\ Institute, Tufts Medical Center, Boston, MA, USA
}

OPEN ACCESS

Edited by:

Jose L. Lanciego,

University of Navarra, Spain

Reviewed by:

Istvan Merchenthaler,

University of Maryland, USA

Marisela Morales,

National Institutes of Health, USA Joel Hahn,

University of Southern California, USA

*Correspondence: Imre Kalló,

Laboratory of Endocrine Neurobiology, Institute of Experimental Medicine, Hungarian Academy of Sciences, Szigony u. 43, 1083 Budapest,

Hungary

kallo.imre@koki.mta.hu

Received: 28 May 2015 Accepted: 30 July 2015 Published: 04 September 2015

Citation:

Kalló I, Molnár CS, Szöke S, Fekete C, Hrabovszky E and

Liposits Z (2015) Area-specific

analysis of the distribution of hypothalamic neurons projecting to the rat ventral tegmental area, with special reference to the GABAergic

and glutamatergic efferents.

Front. Neuroanat. 9:112.

doi: 10.3389/fnana.2015.00112
The ventral tegmental area (VTA) is a main regulator of reward and integrates a wide scale of hormonal and neuronal information. Feeding-, energy expenditure-, stress, adaptation- and reproduction-related hypothalamic signals are processed in the VTA and influence the reward processes. However, the neuroanatomical origin and chemical phenotype of neurons mediating these signals to the VTA have not been fully characterized. In this study we have systematically mapped hypothalamic neurons that project to the VTA using the retrograde tracer Choleratoxin $B$ subunit (CTB) and analyzed their putative gamma-aminobutyric acid (GABA) and/or glutamate character with in situ hybridization in male rats. $23.93 \pm 3.91 \%$ of hypothalamic neurons projecting to the VTA was found in preoptic and 76.27 $\pm 4.88 \%$ in anterior, tuberal and mammillary hypothalamic regions. Nearly half of the retrogradely-labeled neurons in the preoptic, and more than one third in the

\footnotetext{
Abbreviations: Acb, accumbens nucleus; $\mathrm{AH}$, anterior hypothalamic area; $\mathrm{AHA}$, anterior part; $\mathrm{AHC}$, central part; AHP, posterior part; Arc, arcuate nucleus; AVPO, anteroventral preoptic nucleus; ANS, accessory neurosecretory nuclei; DA, dorsal hypothalamic area; DM, dorsomedial hypothalamic nucleus; DMD, dorsal part; DMC, compact part; DMV, ventral part; DTM, dorsal tuberomammillary nucleus; IF, interfascicular nucleus; JPLH, juxtaparaventricular part of lateral hypothalamus; LA, lateroanterior hypothalamic nucleus; LDTg, laterodorsal tegmental nucleus; LHb, lateral habenular nucleus; LM, lateral mammillary nucleus; LPO, lateral preoptic area; ML, medial mammillary nucleus, lateral part; $\mathrm{MM}$, medial mammillary nucleus, medial part; MnPO, median preoptic nucleus; MPA, medial preoptic area; MPO, medial preoptic nucleus; MPOM, medial part; MPOL, lateral part; MTu, medial tuberal nucleus; PA, paraventricular hypothalamic nucleus; PaAP, anterior parvicellular part; PaMM, medial magnocellular part; PaMP, medial parvicellular part; PaDC, dorsal cap; PaLM, lateral magnocellular part; PaV, ventral part; PaPO, posterior part; PaXi, paraxiphoid nucleus; PBP, parabrachial pigmented nucleus; PeF, perifornical nucleus; PeFLH, perifornical part of lateral hypothalamus; PIF, parainterfascicular nucleus; PLH, peduncular part of lateral hypothalamus; PH, posterior hypothalamic nucleus; PHA, posterior hypothalamic area; PHD, posterior hypothalamic area, dorsal part; PMV, premammillary nucleus, ventral part; PMD, premammillary nucleus, dorsal part; PN, paranigral nucleus; $\mathrm{RLi}$, rostral linear nucleus of the raphe; RMTg, rostromedial tegmental nucleus; SCh, suprachiasmatic nucleus; SO, supraoptic nucleus; SPa, subparaventricular zone of the hypothalamus; SuMM, supramammillary nucleus, medial part; SuML, supramammillary nucleus, lateral part; TuLH, tuberal part of lateral hypothalamus; VLPO, ventrolateral preoptic nucleus; VMH, ventromedial hypothalamic nucleus; VMPO, ventromedial preoptic nucleus; VOLT, vascular organ of the lamina terminalis; VTA, ventral tegmental area; VTM, ventral tuberomammillary nucleus.
} 
anterior, tuberal and mammillary hypothalamus appeared in medially located regions. The analyses of vesicular glutamate transporter 2 (VGLUT2) and glutamate decarboxylase 65 (GAD65) mRNA expression revealed both amino acid markers in different subsets of retrogradely-labeled hypothalamic neurons, typically with the predominance of the glutamatergic marker VGLUT2. About one tenth of CTB-IR neurons were GAD65positive even in hypothalamic nuclei expressing primarily VGLUT2. Some regions were populated mostly by GAD65 mRNA-containing retrogradely-labeled neurons. These included the perifornical part of the lateral hypothalamus where $58.63 \pm 19.04 \%$ of CTB-IR neurons were GABAergic. These results indicate that both the medial and lateral nuclear compartments of the hypothalamus provide substantial input to the VTA. Furthermore, colocalization studies revealed that these projections not only use glutamate but also GABA for neurotransmission. These GABAergic afferents may underlie important inhibitory mechanism to fine-tune the reward value of specific signals in the VTA.

Keywords: preoptic area, hypothalamus, VTA, glutamate, GABA, retrograde labeling, in situ hybridization, immunohistochemistry

\section{Introduction}

Information processing through the reward pathway serves to promote survival of the individual, and consequently the species. Signals mediating basic homeostatic and social needs (i.e., hunger and thirst or territorial integrity and partner selection, respectively) reach the neuronal networks of the hypothalamus, which generate responses affecting feeding, energy expenditure, drinking, stress/adaptation and social interaction. Each response carries a reward value through interplay with the reward system of the brain, which appears ultimately in a behavior reflecting the level of reinforcement and motivation. Over the past decades, the central role of the ventral tegmental area (VTA) to regulate reward, motivation and reinforcement learning has been clarified and linked to its major dopaminergic cell population (Tzschentke and Schmidt, 2000; Gardner, 2005; Fields et al., 2007; Arias-Carrión et al., 2010). By using pathway tracing studies with classical neuroanatomical (Phillipson, 1979; Swanson, 1982; Holstege, 1987; Geisler and Zahm, 2005) and the recently elaborated genetic (WatabeUchida et al., 2012) approaches, the contributing principal neuronal connections have been identified. As part of these studies, hypothalamic inputs have been described. Phenotypic and functional characterization of some neurons projecting to the VTA has also been provided. Thus, subsets of neurons in the lateral hypothalamus containing orexin/hypocretin (Cason et al., 2010) or cocaine- and amphetamine-regulated transcript $(\mathrm{CART}) /$ melanin-concentrating hormone $(\mathrm{MCH}$; DallvechiaAdams et al., 2002) have been found to project to the VTA. Furthermore, neurotensin (NT) neurons projecting to the VTA have been identified in the medial (MPO) and lateral (LPO) preoptic area and the rostral lateral hypothalamus (rLH; Geisler and Zahm, 2006), and corticotropin-releasing factor (CRF) neurons in the paraventricular nucleus ( $\mathrm{Pa}$; Rodaros et al., 2007). In addition to these neuromodulatory pathways, tracing of afferents using the classical neurotransmitters glutamate and gamma-aminobutyric acid (GABA) to VTA neurons became also critically important. Of note, the basal activity of dopamine neurons is maintained in the VTA by a tonic excitatory N-methyl-D-aspartate (NMDA) receptor activation, counterbalanced by tonic inhibitory GABA receptor activation making disinhibition bursts and phasic dopamine release possible (Lobb et al., 2011; Morikawa and Paladini, 2011). Although previous studies detected vesicular glutamate transporter 2 (VGLUT2)-expressing glutamatergic afferents from the medial and lateral preoptic area (LPO), as well as from some nuclei of the medial and lateral hypothalamus to the VTA (Geisler et al., 2007; Geisler and Wise, 2008) and a GABAergic pathway from the MPO to the VTA (Tobiansky et al., 2013), the detailed map of hypothalamic neurons projecting to the VTA and the quantitative description of their glutamatergic or GABAergic character are not available.

In the present study, we have (i) systematically mapped hypothalamic nuclei that project to the VTA; and (ii) analyzed the GABA and/or glutamate characters of the identified hypothalamic afferent systems. Retrograde labeling of VTAprojecting hypothalamic neurons with cholera toxin B subunit (CTB) was combined with the isotopic in situ hybridization detection of glutamic acid decarboxylase 65 (GAD65) or VGLUT2 mRNA expression in male rats. The results indicate that the hypothalamus provide a substantial innervation to the VTA from a predominantly ipsilateral side and both from its medial and lateral nuclear compartments. In these communication channels connecting the hypothalamus to the VTA, glutamate and GABA are equally present and may critically contribute to the setting of VTA neuronal activity.

\section{Materials and Methods}

\section{Animals}

Adult male Wistar rats [300-350 g body weight (b.w.)] were used from a local breeding colony at the Medical Gene Technology 
Unit of the Institute of Experimental Medicine. They were housed under controlled lighting (12:12 light-dark cycle; lights on at $07: 00 \mathrm{~h})$ and temperature $\left(22 \pm 2^{\circ} \mathrm{C}\right)$, with access to food and water ad libitum. Experimental protocols were approved by the Animal Welfare Committee of the Institute of Experimental Medicine (No. A5769-01) and were carried out to meet the legal requirements of the European Community (Decree 86/609/EEC). During all surgeries, animals were under deep anesthesia by intraperitoneal administration of a cocktail of ketamine (25 mg/kg b.w.), xylavet ( $5 \mathrm{mg} / \mathrm{kg}$ b.w.) and pipolphen (2.5 mg/kg b.w.) made in saline.

\section{Retrograde Labeling of VTA-Projecting Hypothalamic Neurons with CTB}

To label perikarya of hypothalamic neurons projecting to the VTA, the rats $(n=52)$ were given CTB $(0.5 \%$ solution; \#103, List Biological Laboratories, INC, Campbell, CA, USA) via unilateral iontophoresis ( $5 \mu \mathrm{A}, 7 \mathrm{~s}$ on-off) into the VTA for $20 \mathrm{~min}$. For targeting both mid-rostral and mid-caudal VTA regions, the following stereotaxic coordinates were used, respectively, with reference to the interaural planes; antero-posterior: +3.8 or +2.96 $\mathrm{mm}$, medio-lateral: $+0.6 \mathrm{~mm}$, dorso-ventral: +2 or $+1.8 \mathrm{~mm}$ (Paxinos and Watson, 2005).

\section{Tissue Collection and Processing}

Ten days after tracer injections, the animals were perfused transcardially with $200 \mathrm{ml}$ of $4 \%$ paraformaldehyde solution in $0.1 \mathrm{M}$ sodium phosphate buffer ( $\mathrm{PBS}, \mathrm{pH}$ 7.4). Brains were removed, divided into a rostral and a caudal block with a coronal cut through the middle of the mammillary bodies (antero-posterior plane: interaural plane $4.8 \mathrm{~mm}$; Paxinos and Watson, 2005). Both blocks were post-fixed at $4^{\circ} \mathrm{C}$ in the same solution for a few hours, soaked into $20 \%$ sucrose overnight, then, snap-frozen on powdered dry ice. Thirty [for single-label immunohistochemistry (IHC)] - or 20 [for combined IHC and in situ hybridization histochemistry (ISHH)] $-\mu \mathrm{m}$-thick sections were cut in the coronal plane using a Leica SM 2000R freezing microtome (Leica Microsystems Nussloch GmbH, Nussloch, Germany) and transferred into six-well plates at a consecutive manner to produce six representative collections of sections from each brain. The free-floating sections were stored in antifreeze solution (30\% ethylene glycol; 25\% glycerol; 0.05 $\mathrm{M}$ phosphate buffer; $\mathrm{pH}$ 7.4) at $-20^{\circ} \mathrm{C}$ until the histological staining.

\section{Single-Label Immunohistochemistry to Detect CTB}

One out of the six groups of sections from each brain was processed for plotting the injection sites and mapping the distribution of the labeled cells. The floating sections underwent a series of pre-treatment steps, including permeabilization with Triton X-100 (0.5\% in PBS, $20 \mathrm{~min})$, blocking of endogenous peroxidase activity with $\mathrm{H}_{2} \mathrm{O}_{2}(0.5 \%$ in PBS, 20 min) and preventing non-specific antibody binding to the tissue with normal horse serum ( $2 \%$ in PBS, $10 \mathrm{~min})$. The pre-treatment was followed by sequential incubations in goat
anti-CTB serum $(1: 1,000 ; 24 \mathrm{~h}$; RT; \#703; List Biological Laboratories, INC, Campbell, CA, USA), in biotinylated donkey anti-goat IgG (1:500; 2 h; 705-065-147, Jackson Immunoresearch Laboratories, West Grove, PA, USA) and in avidin-biotin-peroxidase complex (ABC; 1:1,000; 2 h; PK-6100, Vector Laboratories). Between subsequent steps, the sections were rinsed thoroughly in PBS. The peroxidase reaction was developed in a solution containing $5 \%$ diaminobenzidine (DAB), $0.15 \% \mathrm{Ni}$-ammonium-sulfate and $0.006 \% \mathrm{H}_{2} \mathrm{O}_{2}$ in Tris buffer (0.1 M; pH 7.6). The sections were then mounted onto gelatincoated slides, counterstained with $1 \%$ toluidine blue, dehydrated through an ascending ethanol series, cleared in xylene and coverslipped with DPX (44581; Fluka Chemie AG, Buchs, Switzerland).

\section{Combined Detection of CTB and mRNAs for GAD65 or VGLUT2}

\section{Immunohistochemical Detection of CTB}

To phenotype the retrogradely-labeled cells, immunohistochemical detection of CTB was combined with the in situ hybridization detection of GAD65 or VGLUT2 mRNA. Immunohistochemistry preceded the in situ hybridization steps, as preliminary results showed that the detection of CTB is considerably impaired following in situ hybridization. During immunohistochemistry, the tissue mRNAs were protected against enzymatic degradation by adding $1000 \mathrm{U} / \mathrm{ml}$ of heparin sodium salt to the immunohistochemical reagents and by using diethyl pyrocarbonate-pretreated and autoclaved 0.1 M PBS ( $\mathrm{pH}$ 7.4) as a rinsing buffer between the incubation steps. The sections were treated with $0.5 \% \mathrm{H}_{2} \mathrm{O}_{2}$ and $0.2 \%$ Triton X-100 (made in $0.1 \mathrm{M}$ PBS) for $10 \mathrm{~min}$ then blocked against non-specific antibody binding with $2 \%$ bovine serum albumin (BSA; fraction V; Sigma) in PBS for $30 \mathrm{~min}$ and then, transferred into CTB antiserum (1:500) for $24 \mathrm{~h}$. The primary antibodies were reacted with biotin-SP-anti-goat IgG (Jackson ImmunoResearch Laboratories; 1:500) and the $\mathrm{ABC}$ reagent for $1 \mathrm{~h}$ each. Then, biotin tyramide (diluted at 1:1,000 with TBS $/ 0.002 \% \mathrm{H}_{2} \mathrm{O}_{2}$ from a stock prepared in-house according to Adams (1992) and Kerstens et al. (1995) was deposited for $30 \mathrm{~min}$ on the peroxidase sites, as described previously (Hrabovszky et al., 2004a) and the sections processed for the in situ hybridization detection of GAD65 or VGLUT2 mRNA.

\section{Preparation of GAD65 and VGLUT2 Probes}

Preparation and use of an 879-base rat VGLUT2 cDNA (bases 522-1400 of VGLUT2 mRNA; NM_053427.1) have been described earlier (Hrabovszky et al., 2004b, 2005b). The rat GAD65-628 cDNA template (bases 315-944 of NM_012563.1) was kindly made available for these studies by Dr. Sandra L. Petersen (University of Massachusetts, Amherst, MA, USA; Hays et al., 2002). Complementary RNA probes were transcribed in the presence of ${ }^{35} \mathrm{~S}-\mathrm{UTP}$, as described elsewhere (Hrabovszky et al., 2004b). Specificity control experiments including the production and usage of sense probes and second antisense probes recognizing different sequences of target mRNAs have been described in these preceding papers. 


\section{In situ Hybridization Steps}

Prior to hybridization, the sections were acetylated with $0.25 \%$ acetic anhydride in $0.9 \% \mathrm{NaCl} / 0.1 \mathrm{M}$ triethanolamine (Sigma Chemical Company, St. Louis, MO, USA; $\mathrm{pH}$ 8.0) for 10 min, rinsed in standard saline citrate solution $(2 \times \mathrm{SSC}$; $1 \times \mathrm{SSC}=0.15 \mathrm{M} \mathrm{NaCl} / 0.015 \mathrm{M}$ sodium citrate, $\mathrm{pH} 7.0$ ) for $2 \mathrm{~min}$, delipidated in 50,70 and 50\% acetone $(5 \mathrm{~min}$ each) and then rinsed in $2 \times$ SSC again. For hybridization, sections were transferred into microcentrifuge tubes filled with the hybridization solutions (Hrabovszky and Petersen, 2002). To reduce autoradiographic background, $1 \mathrm{M}$ dithiothreitol was included in the hybridization buffer. The hybridization solution contained $40,000 \mathrm{cpm} / \mu \mathrm{l}$ radioisotopic probe and $10 \%$ dextran sulfate. Following hybridization at $52^{\circ} \mathrm{C}$ overnight, the non-specifically bound probes were digested with $20 \mu \mathrm{g} / \mathrm{ml}$ ribonuclease A (Sigma; dissolved in $0.5 \mathrm{M} \mathrm{NaCl} / 10 \mathrm{mM}$ Tris$\mathrm{HCl} / 1 \mathrm{mM}$ EDTA; $\mathrm{pH} 7.8$ ) for $60 \mathrm{~min}$ at $37^{\circ} \mathrm{C}$ and via a stringent treatment in $0.1 \times \mathrm{SSC}$ solution at $65^{\circ} \mathrm{C}$ for $90 \mathrm{~min}$.

\section{Visualization of CTB-immunoreactivity and GAD65 or VGLUT2 mRNA}

Following posthybridization, the biotin tyramide deposits were reacted with streptavidin conjugated to the red fluorochrome Cy3 (Jackson; 1:1000; $1 \mathrm{~h}$ ). Sections were then mounted onto silanized microscope slides, air-dried and processed for autoradiography. To visualize the isotopic signal, the sections were coated with Kodak NTB nuclear track emulsion (Kodak; Rochester, NY, USA; diluted 1:1 with distilled water) which was exposed for 4 weeks, then developed with Kodak processing chemicals. Sections underwent a counterstaining procedure with $10 \mu \mathrm{g} / \mathrm{ml}$ Hoechst (in 0.1 M PBS, pH 7.4, 1 min; Bisbenzimide, Sigma) to enable the distinction of hypothalamic nuclei. After a short rinse in PBS (1 min), the slides were dehydrated in 70, 96, and $100 \%$ ethanol ( $5 \mathrm{~min}$ each), cleared with xylene $(2 \times 5 \mathrm{~min})$, and coverslipped with DPX.

\section{Analysis}

\section{Photomicrography}

Single or mosaic digital photographs of each section were made by using a Zeiss AxioImager M1 microscope mounted with an AxioVision camera and the AxioVision 4.6 software (Zeiss, Göttingen, Germany) and saved as 8-bit TIFF files. The acquired image files were opened in photo-editing software (Adobe Photoshop CS5), composed (cropped, rotated) and adjusted for brightness, contrast, or color balance.

\section{Plotting the Injection Sites}

Sites of tracer deposition within the VTA or hypothalamus were plotted in low-power $(10 \times)$ digital photographs $(150$ pixel/inch) of consecutive sections containing the hypothalamus and the midbrain. The position of plotted areas was evaluated with reference to counterstained neighboring nuclei and visible neuronal tracts. To map VTA-projecting neurons, sections were used from selected brains $(n=28)$ in which the tracer injection was precisely targeted and the focus did not exceed the boundaries of the VTA.

\section{Mapping the Distribution of CTB-Labeled Neurons}

CTB-labeled neurons were mapped in low-power $(10 \times)$, high-resolution digital photographs (150 pixel/inch) of every sixth section of the hypothalamus. Peroxidase-stained specimens were photographed under bright-field illumination. Results of studies using combined immunofluorescence and autoradiography were first photographed with an epifluorescent filter set (excitation of 540-590 nm, band pass of $595 \mathrm{~nm}$, and emission of 600-660 $\mathrm{nm}$ ). Then, the autoradiographic image was captured using the dark-field illumination of silver grains. The fluorescent and autoradiographic images of the same section area were superimposed and processed as separate layers of Adobe Photoshop (PSD) files. Subdivisions of hypothalamic regions were determined by transposition of computerized standard series of rat brain atlas maps (Paxinos and Watson, 2005) in Adobe Photoshop multi-layered images. To adjust the atlas image to the sections produced, sections were counterstained either with $1 \%$ toluidine blue or $10 \mu \mathrm{g} / \mathrm{ml}$ Hoechst. In addition, other sets of sections were stained for hypothalamic peptides [i.e., oxytocin, vasopressin, NT, orexin, enkephalin, pro-opiomelanocortin (POMC), CART, thyrotropin releasing hormone (TRH), calcitonin gene related peptide (CGRP), $\mathrm{CRH}$, and $\mathrm{MCH}$ ] together with CTB (data not shown). The staining patterns obtained (beside the pattern generated by counterstaining, and the distribution of GAD65 and VGLUT2 transcripts) helped us delineate the hypothalamic subdivisions in our figures.

\section{Quantification of VTA-Projecting GAD65- or VGLUT2 Expressing Neurons}

Colocalization level of the immunofluorescent signal for CTB and the autoradiographic signal for GAD65 or VGLUT2 mRNA was analyzed in multi-layered digital images. For each region and brain, two to six photographs (representing coronal sections $120 \mu \mathrm{m}$ apart from each other) were used for the analysis. A CTB-immunoreactive cell was considered doublelabeled if the accumulation of the radioactive $S^{35}$ hybridization signal (the silver grain cluster) overlapped largely with the somato-dendritic shape of the underlying stained cell and the density of the grains (area covered by silver grains/selected total area) was at least three times higher than in the background (the area fraction of silver grains in a surrounding background region), as determined with ImageJ software (public domain at http://rsb.info.nih.gov/ij/download/src/). For each area, the percentages of double-labeled cells were calculated and the data were expressed as the mean \pm standard error.

\section{Results}

\section{Cholera Toxin B Subunit Injections into the VTA Nuclear Complex}

From 52 targeted CTB injections, 28 were restricted to the VTA. Tracer deposition was distributed variably among the different subnuclei of the VTA i.e., the rostral part of the VTA (VTAR), the parabrachial pigmented nucleus (PBP), the 

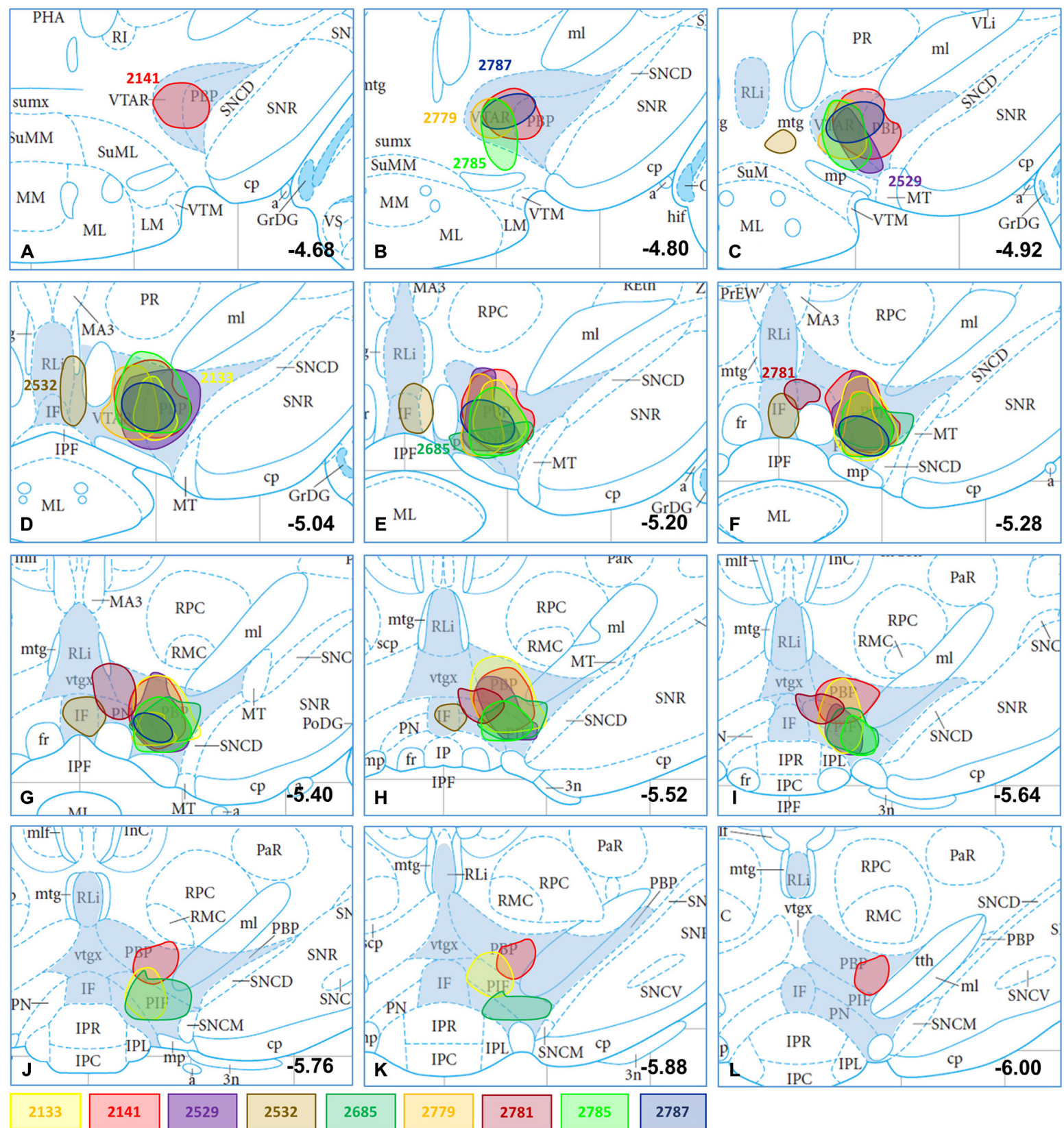

2141

2529

2532

FIGURE 1 | CTB-immunoreactive injection sites plotted in mesencephalic section images; the location and dimension of selected injection sites (\#2133, \#2141, \#2529, \#2532, \#2685, \#2779, \#2781, \#2785, 2787) demonstrated with differently colored spots in atlas figures (Bregma levels from -4.68 to -6.00; A-L) according to Paxinos and Watson (2005). Subnuclei of the VTA (VTAR, PBP, PN, PIF, RLi, IF) are shaded in blue. The plots at different Bregma levels indicate the antero-posterior spread of the corresponding CTB deposit. The atlas figures modified were originally published in The Rat Brain in Stereotaxic Coordinates: The New Coronal Set. Fifth edition, George Paxinos and Charles Watson, Copyright Elsevier (2005).

parainterfascicular nucleus (PIF), the paranigral nucleus (PN), the interfascicular nucleus (IF) and/or the rostral linear nucleus of the raphe (RLi; Oades and Halliday, 1987; Bourdy and Barrot, 2012). Nine different injections were selected to illustrate (Figure 1; Table 1) the results of the mapping and phenotypic characterization. These nine cases differed from each other in their antero-posterior $(0.74 \pm 0.1)$ and dorso-ventral $(0.51 \pm$
$0.04)$ dimensions as well as their location within the VTA. They were expanding between Bregma levels $(-4.68)$ and $(-6.00)$, with central sites located at $(-5.04)$ and $(-5.64$; Table 1$)$. With the exception of medial injection sites (e.g., \#2532), CTB injections affected always the PBP and PN exhibiting variably sized deposition of the tracer (Table 1; case \#2141 is illustrated with a photo in Figure 2A). 
TABLE 1 | Characterization of the rostro-caudal spread of the different injection sites.

\begin{tabular}{|c|c|c|c|c|c|c|c|c|c|c|}
\hline \multirow[b]{2}{*}{ Case\# } & \multirow[b]{2}{*}{ VTAR } & \multirow[b]{2}{*}{ PBP } & \multirow[b]{2}{*}{ PN } & \multirow[b]{2}{*}{ PIF } & \multirow[b]{2}{*}{ RLi } & \multirow[b]{2}{*}{ IF } & \multicolumn{3}{|c|}{ Bregma AP $(\mathrm{mm})$} & \multirow{2}{*}{$\begin{array}{l}\text { RCDist } \\
(\mathrm{mm})\end{array}$} \\
\hline & & & & & & & B & C & $\mathbf{E}$ & \\
\hline 2133 & + & ++++++++ & ++ & ++++ & - & - & -5.04 & -5.28 & -5.88 & 0.84 \\
\hline 2141 & ++++ & ++++++++++++ & + & ++ & - & - & -4.68 & -5.20 & -6.00 & 1.44 \\
\hline 2529 & ++ & ++++++ & ++++ & ++ & - & - & -4.92 & -5.20 & -5.64 & 0.72 \\
\hline 2532 & - & - & - & - & ++ & +++++ & -4.92 & -5.04 & -5.52 & 0.60 \\
\hline 2685 & - & ++++++ & +++++++ & ++++ & - & - & -5.20 & -5.64 & -5.88 & 0.68 \\
\hline 2779 & +++ & ++++ & +++ & - & - & - & -4.80 & -5.20 & -5.40 & 0.60 \\
\hline 2781 & - & +++ & +++ & ++ & + & + & -5.28 & -5.28 & -5.64 & 0.36 \\
\hline 2785 & +++ & ++++++ & ++++++ & ++ & - & - & -4.80 & -5.20 & -5.64 & 0.84 \\
\hline 2787 & +++ & ++++++ & ++ & - & - & - & -4.80 & -5.28 & -5.40 & 0.60 \\
\hline
\end{tabular}

The number of crosses refers to the number of sections containing CTB deposits in a given anatomical subdivision of VTA. B = the level of first appearance of the deposit, $C=$ the level of the central portion of the deposit, $E=$ the level of last appearance of the deposit, RCDist = rostro-caudal extension of the deposit.

\section{Characterization of Retrograde Labeling in the Hypothalamus}

In accordance with previous tracing studies (Phillipson, 1979; Swanson, 1982; Geisler and Zahm, 2005; Watabe-Uchida et al., 2012), CTB-IR neurons were detected in brain regions known to be part of the reward circuitry e.g., nucleus accumbens (NAc; not shown), prefrontal cortex (not shown), amygdala and extended amygdala (EA; Figure 2B). Within the hypothalamus, the retrogradely-labeled CTBimmunoreactive perikarya exhibited a predominantly ipsilateral distribution as illustrated in representative coronal sections at the level of the paraventricular nucleus (Figure 2B) and the dorso- and ventromedial nuclei (Figure 2C). From the retrogradely-labeled hypothalamic neurons the majority of

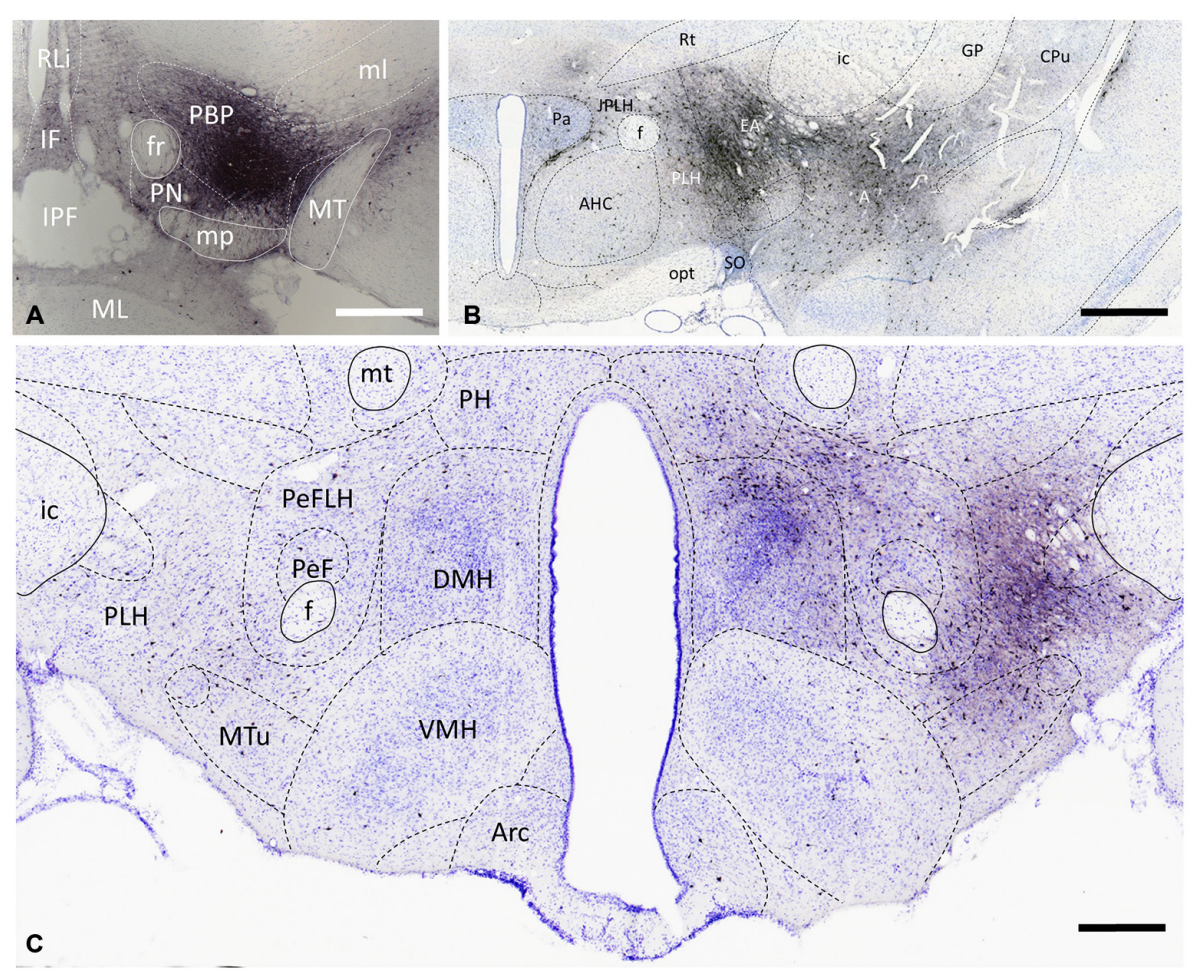

FIGURE 2 | Distribution of VTA-projecting neurons in the rat brain visualized by immunohistochemical detection of the retrograde tract tracer, cholera toxin B subunit (CTB). A representative CTB deposition (Case \#2141) which is restricted to the parabrachial pigmented (PBP) nucleus of the VTA (at Bregma -5.2) is shown in (A). Retrogradely labeled cells are present bilaterally with significantly higher number on the ipsilateral side, as shown in the area of the paraventricular (B) and dorsomedial (C) nuclei. CTB-immunoreactive cells are in the amygdala (A) and extended amygdala (EA) complexes, as well as in lateral, and medial hypothalamic areas. Boundaries of brain regions (dashed lines) correspond to those delineated in the rat brain atlas [75]. Sections were counterstained with Toluidine blue. Scale bars: $1000 \mu \mathrm{m}$ for $(\mathbf{A}, \mathbf{B})$, and $500 \mu \mathrm{m}$ for $(\mathbf{C})$. 
descending fibers gathered in the medial forebrain bundle, resulting in an increasing rostro-caudal accumulation of CTBimmunoreactive axons also on the ipsilateral side (Figures 2B,C). Quantitative analysis of CTB-IR perikarya in nine different brains revealed similar distribution patterns. However, the number of retrogradely labeled cells differed from brain to brain. More than half of VTA-projecting neurons was found in anterior and mid hypothalamic regions $(57.35 \pm 5.04 \%$ of all counted CTB neurons); the preoptic areas and the posterior hypothalamic regions contained, respectively, $23.93 \pm 3.91 \%$ and $18.92 \pm 4.63 \%$ of the CTB-positive neurons. Although the lateral preoptic and lateral hypothalamic regions showed a more intense retrograde labeling in comparison with immunostained cellular and nuclear constituents of the medial hypothalamus (Figures 2B,C), overall nearly half $(11.24 \pm 2.52 \%)$ of the retrogradely-labeled neurons in the preoptic area, and more than one third $(28.39 \pm 3.22 \%)$ of them in the anterior, tuberal and mammillary hypothalamus appeared in medially located subdivisions; i.e., the MPA, the median preoptic, paraventricular, dorsomedial, ventromedial, mammillary nuclei and the SUM.

\section{Distribution and Transmitter Phenotype of Hypothalamic Neurons Projecting to VTA Preoptic Input of the VTA}

The retrogradely labeled, CTB-IR neurons in the preoptic area were equally shared by the medial $(11.24 \pm 2.52 \%$, calculated for all CTB positive neurons) and lateral (12.69 $\pm 1.67 \%)$ subdivisions. In the midline, relatively high numbers of CTBIR neurons were found in the median preoptic nucleus (MnPO). In contrast, the vascular organ of the lamina terminalis (VOLT) contained retrogradely-labeled cells rarely (Table 2; Figure 3A). In medial preoptic regions, the majority of CTB-IR neurons were in the medial preoptic nucleus (MPO), predominantly in its lateral subdivision. A substantial number of labeled neurons was also detected in the MPA (Table 2; Figures 3B-D). No or very few CTB-IR neurons were found in the anteroventral preoptic nucleus (AVPO) or the ventromedial and ventrolateral preoptic nuclei (VMPO and VLPO; Table 2; Figure 3A). In these preoptic subdivisions, the VGLUT2 mRNA expressing, VTAprojecting neurons (VOLT: $44.44 \pm 9.11 \%$, MnPO: $51.43 \pm$ 2.41\%, AVPO: $55.77 \pm 5.77 \%$, MPA: $36.55 \pm 5.85 \%$, MPO: 45.78 $\pm 3.90 \%)$ predominated over the GAD65 mRNA containing neurons projecting to the VTA (VOLT: $3.12 \pm 3.12 \%$, MnPO: $9.30 \pm 3.87 \%$, AVPO: $5.00 \pm 5.00,18.26 \pm 2.14$, MPO: $14.17 \pm 6.66 \%$; Table 3 ). In lateral preoptic regions, intensely labeled CTB-IR neurons appeared in large number within the lateral preoptic area (LPO; Table 2; Figures 3A-C). The glutamate and GABA phenotypes were represented similarly $(31.65 \pm 3.47 \%$ vs. $29.90 \pm 13.05 \%)$ in this brain region (Table 3).

\section{Afferents of VTA Originating from Different} Subdivisions of the Anterior Hypothalamus

The hypothalamic $\mathrm{Pa}$ contributed to the afferent supply of the VTA in a subnucleus-specific manner (Table 2). Moderate number of CTB-IR neurons were observed in the medial (PaMP; Figures $3 \mathbf{E}-\mathbf{G})$ and posterior $(\mathrm{PaPO})$ parvocellular subdivisions
(Figure 3G). Relatively few VTA-projecting neurons appeared in the ventral parvicellular ( $\mathrm{PaV}$; Figures 3D-F) and medial magnocellular (PaMM) subdivisions (Figure 3E) and only very few CTB-IR cells were located in the lateral magnocellular $(\mathrm{PaLM})$ and the dorsal cap (PaDC) subdivisions (Figure 3F). In addition, moderate numbers of CTB-IR neurons were also observed in the immediate vicinity of the $\mathrm{Pa}$, in the juxtaparaventricular part of the lateral hypothalamus (JPLH) and the subparaventricular zone of the hypothalamus (SPa; Figures 3E-G). The majority of the VTA-projecting neurons in the $\mathrm{Pa}(39.61 \pm 2.45 \%)$ and JPLH $(40.65 \pm 3.77 \%)$ were identified as glutamatergic (Table 3; Figure 4). In contrast, nearly equal subsets of the CTB-immunopositive neurons were labeled for glutamatergic $(24.05 \pm 8.39 \%)$ and GABAergic $(22.40 \pm 7.88 \%)$ mRNA markers in the SPa region (Table 3; Figures 4E,F).

Very few CTB accumulating neurons were detected in the accessory neurosecretory nuclei (ANS; Table 2; Figures 3E,F), located at the level of the $\mathrm{Pa}$ above the fornix. The labeled neurons were virtually absent from the other major magnocellular neurosecretory nucleus, the supraoptic nucleus (SO), as well as from the suprachiasmatic nucleus (SCh). The anterior hypothalamic area contained only a few labeled cells. (Table 2; Figures 2B, 3D-G), contrasting the peduncular part of the lateral hypothalamus (PLH), which was heavily populated by a mixture of glutamatergic $(29.30 \pm 8.39 \%)$ and GABAergic $(33.83 \pm 4.8 \%)$, neurons projecting to VTA (Tables 2, 3; Figure 2B).

\section{Projections to the VTA from the Tuberal Region of the Hypothalamus}

The hypothalamic dorsomedial nucleus (DMH) contained a substantial number of CTB-IR neurons in its dorsal subdivision, mainly at caudal levels (Table 2; Figure 3J). In the compact and ventral subdivisions, very few or no CTB-IR neurons were detected (Figures 3I,J). In this nucleus, the VTA-projecting glutamatergic neurons predominated over the GABAergic ones $(43.63 \% \pm 7.92$ vs. $23.66 \pm 14.24 \%$, Table 3$)$.

The ventromedial nucleus (VMH) contained a moderate number of CTB-IR neurons (Table 2) which showed no preferential location in either the dorsomedial, the central or the ventrolateral subdivisions (Figures $\mathbf{2 C}, \mathbf{3 H}, \mathbf{K}, \mathbf{L}$ ). The majority of the labeled VMH neurons expressed VGLUT2 mRNA (59.24 \pm $8.52 \%)$. The arcuate nucleus (Arc) contained only a few CTBIR neurons (Figures 2C, 3K-M; Table 2). They consisted of a mixture of cells with glutamatergic (41.67 $\pm 8.68 \%)$ and GABAergic $(41.10 \pm 17.44 \%)$ phenotypes (Table 3).

In the mid-level of the hypothalamus, its lateral compartment was heavily populated by CTB-accumulating neurons. The labeled cells occurred in the perifornical (PeFLH) and tuberal (TuLH) subdivisions of the lateral hypothalamus, in the perifornical $(\mathrm{PeF})$ and medial tuberal nuclei (MTu; Figures $2 \mathrm{C}$, $3 \mathrm{H}-\mathrm{L}$ ). Contrasting more rostral regions, the perifornical $(\mathrm{PeFLH})$ and the tuberal $(\mathrm{TuLH})$ parts of the $\mathrm{LH}$ showed a predominance for GABAergic VTA-projecting neurons over those expressing the glutamatergic marker VGLUT2 mRNA (the frequency of VGLUT2 vs. GAD65 mRNA containing neurons was $32.64 \pm 12.75 \%$ vs. $40.24 \pm 8.13 \%$ in the TuLH and $30.95 \pm$ 17.97 vs. $58.63 \pm 19.04 \%$ in the PeFLH; Table 3). 
TABLE 2 | Relative abundance of retrograde labeled cells resulting from six separate injections of CTB into the ventral tegmental area (VTA) of male rats.

\begin{tabular}{|c|c|c|c|c|c|c|}
\hline Hypothalamic regions & Case \#2133 & Case \#2141 & Case \#2529 & Case \#2532 & Case \#2685 & Case \#2785 \\
\hline Vascular organ of the lamina terminalis (VOLT) & $+/-$ & $+/-$ & $+/-$ & $+1-$ & $+/-$ & $+/-$ \\
\hline Medial preoptic area (MPA) & +++ & +++ & + & ++ & +++ & +++ \\
\hline Median preoptic nucleus (MnPO) & +++ & ++ & $+/-$ & ++ & ++ & +++ \\
\hline Medial preoptic nucleus (MPO) & ++++ & ++++ & + & ++ & ++ & ++++ \\
\hline Medial part (MPOM) & ++ & ++ & $+/-$ & + & ++ & ++ \\
\hline Lateral part (MPOL) & ++ & ++ & + & ++ & + & +++ \\
\hline Anteroventral preoptic nucleus (AVPO) & $+/-$ & $+/-$ & - & - & $+/-$ & $+/-$ \\
\hline Ventromedial preoptic nucleus (VMPO) & $+/-$ & $+/-$ & - & - & $+1-$ & - \\
\hline Ventrolateral preoptic nucleus (VLPO) & $+/-$ & $+/-$ & - & $+/-$ & - & $+/-$ \\
\hline Lateral preoptic area (LPO) & +++ & ++++ & ++ & ++++ & ++++ & ++++ \\
\hline Suprachiasmatic nucleus (SCh) & $+1-$ & - & - & - & $+/-$ & $+/-$ \\
\hline Supraoptic nucleus (SO) & $+/-$ & - & - & - & $+/-$ & - \\
\hline Paraventricular hypothalamic nucleus (Pa) & +++ & +++ & + & $+1-$ & ++ & +++ \\
\hline Anterior parvicellular part (PaAP) & ++ & $+1-$ & - & - & $+/-$ & + \\
\hline Medial magnocellular part (PaMM) & ++ & ++ & - & $+/-$ & $+/-$ & + \\
\hline Medial parvicellular part (PaMP) & ++ & + & $+/-$ & - & + & ++ \\
\hline Dorsal cap (PaDC) & $+/-$ & $+/-$ & $+/-$ & - & $+/-$ & $+/-$ \\
\hline Lateral magnocellular part (PaLM) & + & + & $+/-$ & $+/-$ & $+/-$ & + \\
\hline Ventral part (PaV) & + & ++ & + & $+/-$ & $+/-$ & + \\
\hline Posterior part (PaPo) & ++ & + & + & $+/-$ & + & ++ \\
\hline Accessory neurosecretory nuclei (ANS) & + & $+/-$ & - & - & $+/-$ & $+/-$ \\
\hline Juxtaparaventricular part of lateral hypothalamus (JPLH) & ++ & ++ & $+/-$ & + & $+1-$ & ++ \\
\hline Subparaventricular zone of the hypothalamus (SPa) & ++ & ++ & + & $+1-$ & $+/-$ & ++ \\
\hline Anterior hypothalamic area $(\mathrm{AH})$ & +++ & ++ & + & ++ & + & ++ \\
\hline Anterior part (AHA) & + & + & - & $+/-$ & $+/-$ & + \\
\hline Central part (AHC) & ++ & + & $+/-$ & + & $+/-$ & + \\
\hline Posterior part (AHP) & + & $+/-$ & $+/-$ & $+/-$ & $+/-$ & + \\
\hline Lateroanterior hypothalamic nucleus (LA) & + & + & - & + & $+/-$ & + \\
\hline Arcuate nucleus (Arc) & + & ++ & + & + & + & + \\
\hline Ventromedial hypothalamic nucleus (VMH) & +++ & +++ & + & ++ & ++ & +++ \\
\hline Peduncular part of lateral hypothalamus (PLH) & +++++ & +++++ & +++ & ++++ & ++++ & +++++ \\
\hline Tuberal part of lateral hypothalamus (TuLH) & +++ & +++ & ++ & ++ & +++ & +++ \\
\hline Dorsal hypothalamic area (DA) & ++ & +++ & $+/-$ & + & + & ++ \\
\hline Dorsomedial hypothalamic nucleus (DM) & +++ & +++ & $+/-$ & ++ & ++ & +++ \\
\hline Dorsal part (DMD) & +++ & +++ & $+/-$ & ++ & ++ & +++ \\
\hline Compact part (DMC) & + & + & - & $+/-$ & $+/-$ & + \\
\hline Ventral part (DMV) & + & + & $+/-$ & + & + & + \\
\hline Perifornical nucleus (PeF) & ++ & ++ & $+/-$ & + & + & ++ \\
\hline Perifornical part of lateral hypothalamus (PeFLH) & +++ & +++ & +++ & +++ & +++ & ++++ \\
\hline Medial tuberal nucleus (MTu) & ++ & ++ & $+/-$ & + & + & ++ \\
\hline Posterior hypothalamic nucleus (PH) & +++ & +++ & ++ & +++ & ++ & +++ \\
\hline Posterior hypothalamic area (PHA) & + & + & $+/-$ & $+1-$ & + & + \\
\hline Premammillary nucleus, ventral part (PMV) & + & + & $+/-$ & + & + & + \\
\hline Premammillary nucleus, dorsal part (PMD) & + & + & $+/-$ & ++ & $+/-$ & + \\
\hline Medial mammillary nucleus, medial part (MM) & +++ & ++ & $+/-$ & +++ & $+/-$ & ++ \\
\hline Medial mammillary nucleus, lateral part (ML) & ++ & ++ & $+1-$ & +++ & - & ++ \\
\hline Lateral mammillary nucleus (LM) & + & + & $+/-$ & ++ & $+/-$ & + \\
\hline Supramammillary nucleus, medial part (SuMM) & ++ & + & + & ++ & + & ++ \\
\hline Supramammillary nucleus, lateral part (SuML) & +++ & ++ & + & ++ & +++ & +++ \\
\hline Dorsal tuberomammillary nucleus (DTM) & $+/-$ & $+1-$ & $+1-$ & $+1-$ & $+1-$ & $+1-$ \\
\hline Ventral tuberomammillary nucleus (VTM) & + & $+/-$ & $+/-$ & + & $+/-$ & $+/-$ \\
\hline
\end{tabular}

The CTB depositions appeared in different subnuclei of the VTA (between Bregma -4.68 and -6.00). The relative abundance of labeling is characterized using a semi-quantitative grading scale: -, 0; +/-, 1-10; +, 10-30; ++, 30-100; +++, 100-300; ++++, 300-1000; +++++, 1000-2000. The brain region hierarchy follows that of the Paxinos and Watson brain atlas.

\section{Outflow from the Mammillary Region of the Hypothalamus to the VTA}

Roughly one fifth of the VTA-projecting neurons were found in the caudal hypothalamic nuclei and regions (18.92 $\pm 4.63 \%)$. As elsewhere, CTB-labeled neurons consisted of mixed GABAergic and glutamatergic populations. Among the CTB-labeled cells, a substantial population of VTA-projecting neurons was found in the posterior hypothalamic nucleus ( $\mathrm{PH}$; Table 2; Figures 2C, 3J,N). CTB-IR neurons were also present in low numbers in the posterior hypothalamic area, and the dorsal and ventral parts of the premammillary nuclei (Table 2; Figures 3M,O), and nearly absent from the dorsal and ventral tuberomammillary nuclei 

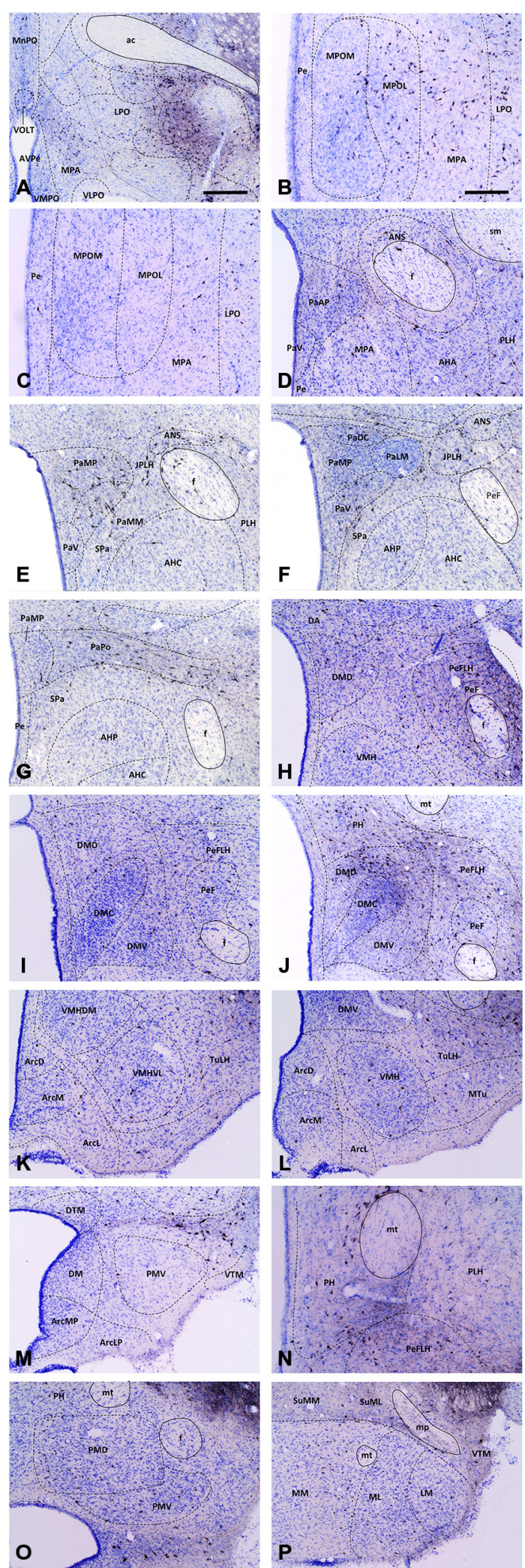

FIGURE 3 | Medium-power micrographs of representative coronal sections depicting main hypothalamic areas and nuclei of a

(Continued)

\section{FIGURE 3 | Continued}

CTB-injected brain (Case \#2133). At certain rostro-caudal levels, the medial preoptic (A-C), paraventricular (D-G), dorsomedial $\mathbf{( H - J , L , M ) ~ a n d ~ p o s t e r i o r ~}$ hypothalamic $(\mathbf{J}, \mathbf{N}, \mathbf{O})$ nuclei exhibit high accumulation of VTA-projecting CTB-IR neurons. In contrast, the relatively few CTB-IR neurons in the ventromedial $(\mathbf{K}, \mathbf{L})$, arcuate $(\mathbf{K}-\mathbf{M})$, ventral and dorsal premammillary $(\mathbf{O})$ and supramammillary and mammillary nuclei $\mathbf{( P )}$ are more-or-less evenly distributed through the rostro-caudal extent of these areas. Boundaries of brain regions (dashed lines) correspond to those delineated in the rat brain atlas. Scale bars: $500 \mu \mathrm{m}$ in (A), $250 \mu \mathrm{m}$ in (B-P).

(Table 2; Figures 3M,P). VTA-projecting neurons also occurred in the supramammillary nuclei (SuM) with the majority of the cells in the lateral part of this nucleus and the mammillary (MM) nuclei, where primarily the medial nucleus was labeled (Table 2; Figure 3P).

\section{Discussion}

In the present report, we provide a detailed map of hypothalamic neurons that are wired to the VTA and demonstrate the differential co-localization of the employed tracer, CTB with GAD65 and VGLUT2 mRNAs in distinct nuclei and welldefined areas of the hypothalamus. The findings indicate that: (i) the hypothalamic input to VTA is bilateral with an ipsilateral predominance; (ii) in addition to the lateral hypothalamus, nuclei located in the medial segment of the hypothalamus also send intense neuronal projections to the VTA; (iii) composite nuclei provide subnucleus-specific, differential inputs; and (iv) a mixed glutamatergic and GABAergic population of preoptic/hypothalamic neurons communicates from both sides with the brainstem reward center, the VTA.

\section{Distribution of Neurons Projecting to the VTA in Hypothalamic Areas}

The hypothalamic areas and nuclei showed a differential distribution of CTB immunoreactive neurons, exhibiting variations from abundantly to poorly populated regions. Similar distribution patterns were obvious in all injected animals suggesting the independence of the phenomenon from the size of CTB deposition. Thus, similarly to other investigators (Phillipson, 1979; Geisler and Zahm, 2005; Watabe-Uchida et al., 2012), we found a large number of VTA-projecting neurons in the lateral preoptic and lateral hypothalamic areas (LHs). In contrast, no or very few CTBimmunoreactive cells were observed in the ventrolateral preoptic, supraoptic and suprachiasmatic nuclei. Our mapping strategy of analyzing sections $180 \mu \mathrm{m}$ apart from each other often revealed robust rostro-caudal differences as well in the number of CTB-IR cells within certain hypothalamic subdivisions i.e., the medial preoptic and the dorsomedial nuclei. This finding indicates the topographical segregation of neurons projecting to the VTA within the same nuclei. Thus, the majority of neurons projecting to the VTA were found in the rostral part of the medial preoptic area, which controls the appetitive component of the male sexual behavior (Balthazart and Ball, 2007), whereas only a few CTB-IR neurons 
TABLE 3 | Colocalization percentages of GAD65 or VGLUT mRNA signals in VTA-projecting CTB-IR neurons in various hypothalamic areas.

\begin{tabular}{|c|c|c|c|c|c|c|}
\hline $\begin{array}{l}\text { Hypothalamic } \\
\text { regions }\end{array}$ & $\begin{array}{l}\text { GAD (+) CTB (+) } \\
\text { of all CTB (+) } \\
\text { Mean } \pm \text { SEM (\%) }\end{array}$ & $\begin{array}{l}\text { GAD (+) } \\
\text { CTB (+) } \\
n_{\text {cells }}\end{array}$ & $\begin{array}{l}\text { Only } \\
\text { CTB (+) } \\
n_{\text {cells }}\end{array}$ & $\begin{array}{l}\text { VGLUT2 (+) CTB (+) } \\
\text { of all CTB (+) } \\
\text { Mean } \pm \text { SEM (\%) }\end{array}$ & $\begin{array}{l}\text { VGLUT2 } \\
(+) \text { CTB (+) } \\
n_{\text {cells }}\end{array}$ & $\begin{array}{l}\text { Only } \\
\text { CTB (+) } \\
n_{\text {cells }}\end{array}$ \\
\hline VOLT & $3.12 \pm 3.46$ & 1 & 10 & $44.44 \pm 9.11$ & 19 & 18 \\
\hline MPA & $18.26 \pm 2.14$ & 83 & 312 & $36.55 \pm 5.85$ & 148 & 198 \\
\hline $\mathrm{MnPO}$ & $9.30 \pm 3.87$ & 13 & 81 & $51.43 \pm 2.41$ & 65 & 58 \\
\hline MPO & $14.17 \pm 6.64$ & 83 & 312 & $45.78 \pm 3.90$ & 174 & 201 \\
\hline AVPO & $5.00 \pm 5.61$ & 1 & 17 & $55.77 \pm 5.77$ & 9 & 7 \\
\hline LPO & $29.90 \pm 13.05$ & 51 & 181 & $31.65 \pm 3.47$ & 88 & 205 \\
\hline $\mathrm{Pa}$ & $10.28 \pm 0.66$ & 26 & 227 & $39.61 \pm 2.45$ & 144 & 216 \\
\hline JPLH & $9.43 \pm 3.41$ & 23 & 141 & $40.65 \pm 3.77$ & 100 & 149 \\
\hline $\mathrm{SPa}$ & $22.40 \pm 7.88$ & 17 & 43 & $24.05 \pm 8.39$ & 31 & 55 \\
\hline Arc & $41.10 \pm 17.44$ & 11 & 13 & $41.67 \pm 8.68$ & 13 & 19 \\
\hline VMH & $11.50 \pm 6.87$ & 9 & 89 & $59.24 \pm 8.52$ & 81 & 22 \\
\hline $\mathrm{DMH}$ & $23.66 \pm 14.24$ & 42 & 66 & $43.63 \pm 7.92$ & 64 & 66 \\
\hline PLH & $29.30 \pm 4.87$ & 330 & 767 & $33.83 \pm 4.80$ & 344 & 671 \\
\hline TuLH & $40.24 \pm 8.13$ & 54 & 64 & $32.64 \pm 12.75$ & 30 & 79 \\
\hline PeFLH & $58.63 \pm 19.04$ & 84 & 36 & $30.95 \pm 17.97$ & 36 & 54 \\
\hline
\end{tabular}

Data are presented as mean values of four animals \pm SEM.

were observed in the caudal half of the medial preoptic area and the adjacent rostral part of the anterior hypothalamic area, which have been implicated in attack against a male intruder (Veening et al., 2005) and in drinking regulation (Swanson et al., 1978). In the DMH, which is a site playing important physiological role in the circadian regulation of food intake and related anticipatory activation (Poulin and Timofeeva, 2008; Verhagen et al., 2011), the VTA-projecting neurons were found primarily in the dorsal and caudal subdivisions. It is currently unclear, whether the uneven distribution and different abundance of neurons projecting to the VTA in certain hypothalamic subdivisions reflect a function-dependent participation in direct communication with VTA.

To provide semi-quantitative measures for regional abundance and differences in the VTA-projecting neurons, we characterized the different hypothalamic areas and nuclear subdivisions using a 7-point scale i.e., characterizing brain regions exhibiting no or very few retrogradely-labeled neurons with-or \pm signs, and those containing from ten to several thousand of CTB-positive cells with one to five plus signs. By using such approach, we could include in the analyses also hypothalamic nuclei containing relatively few neurons projecting to the VTA, and provide cumulative data for CTB-IR neurons occupying medially located subdivisions of the hypothalamus. The summary of our analyses confirmed previous observations, that proportionally fewer CTB-IR cells were on the contralateral than on the ipsilateral sides, but also produced some unexpected results i.e., half of the neurons projecting to the VTA in the preoptic region and one third in the anterior, tuberal and mammillary hypothalamus occurred in medial subdivisions.

Thus, significant subsets of neurons projecting to the VTA have been identified in the $\mathrm{Pa}, \mathrm{DM}$, and VMH. A few neurons were also observed to project to the VTA from the Arc. While we recognize that the low number of neurons traced from the VTA does not necessarily indicate a weak functional connectivity, it seems likely that the direct link between the primary target site of the metabolic signals, the Arc and the VTA is inferior to the indirect connections. Of note, the paucity of CTB-immunoreactive cells in the Arc seems to be in conflict with the results of AGRP- and $\beta$-endorphinimmunohistochemical studies showing relatively high density of immunoreactive fibers in the VTA (Finley et al., 1981; Dietrich et al., 2012). Since AGRP is exclusively synthetized by Arc NPY neurons (Chen et al., 1999) and the majority of $\beta$-Endorphin derive from Arc POMC neurons (Finley et al., 1981), we predicted that VTA injections of CTB would trace higher numbers of Arc neurons. The reason for not seeing more retrogradely labeled cells in the Arc might be that AGRP and $\beta$-endorphin-immunoreactive fibers pass through the VTA without establishing synaptic contact there. Another possibility is that only few AGRP and/or $\beta$-endorphin cells project to the VTA but they establish a particularly rich axonal arborization there. Further studies are required to clarify these issues.

In our present study, we found that hypothalamic neurons projecting to the VTA often occupy a position in the close proximity, but outside the borders, of major nuclei and pathways. Such accumulation of CTB-IR neurons was observed next to the hypothalamic paraventricular nucleus in the SPa and the JPLH and around the ventral and dorsal premammillary nuclei and in the caudal extension of the tuberal part of the lateral hypothalamus. This preferential distribution in the vicinity of certain hypothalamic nuclei suggests integrative functions for these neurons. By receiving limbic inputs (Ericson et al., 1991; Hahn and Swanson, 2010, 2012) and through connections with resident cells of the $\mathrm{Pa}, \mathrm{SO}, \mathrm{DM}, \mathrm{VMH}, \mathrm{PMV}$, and PMD, these neurons may communicate stress- (Champagne et al., 1998), metabolic(Park and Carr, 1998) and/or reproduction-related signals (Di Sebastiano and Coolen, 2012) to VTA to initiate motivation 

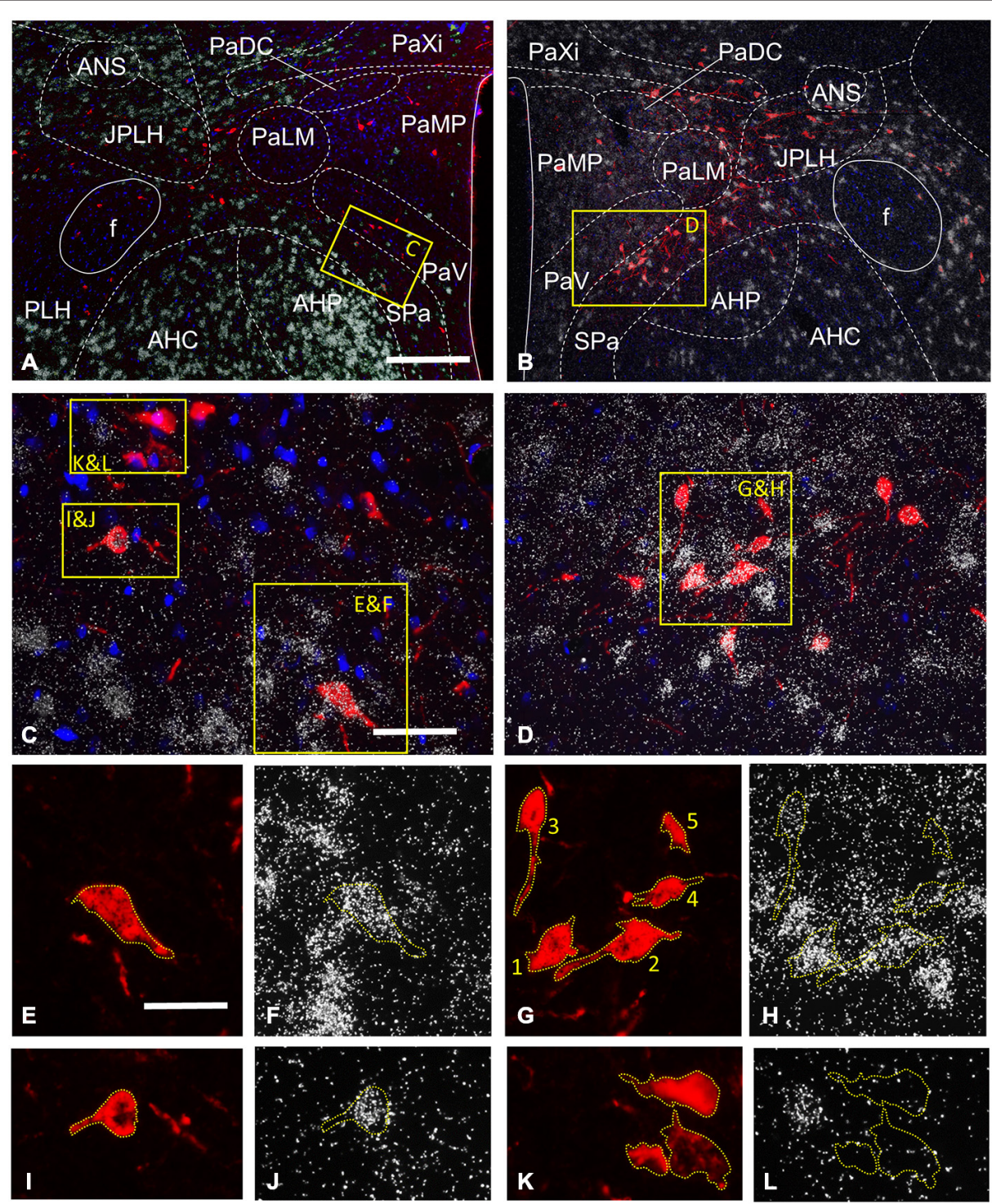

FIGURE 4 | Expression of the GABAergic (GAD 65 mRNA) and glutamatergic (VGLUT2 mRNA) markers by CTB-labeled hypothalamic neurons projecting to the VTA, as detected in two representative sections by the combined use of in situ hybridization (ISHH) and immunohistochemistry. At the level of the paraventricular nucleus (Pa), CTB-IR neurons are detected in different subnuclei of the Pa, the juxtaparaventricular (JPLH) and peduncular (PLH) parts of the lateral hypothalamus and the subparaventricular zone of the hypothalamus (Spa; $\mathbf{A}, \mathbf{B})$. Neurons with intense GAD65 mRNA expression are found in the anterior hypothalamic nuclei (AHP and AHC), the JPLH and SPa, and a few scattered cells also appear in the Pa (A). A moderate vGLUT2 mRNA signal is present in the $\mathrm{Pa}$, in contrast with the AHP, AHC, JPLH and SPa which contain neurons with high level of expression (B). The yellow enframed areas in (A,B) are magnified to (C,D), respectively. These images illustrate the SPa and the neighboring AHP and the ventral part of the Pa at medium power. The indexed yellow boxes are further magnified to single channel images, which show the signal either for CTB $(\mathbf{E}, \mathbf{G}, \mathbf{I}, \mathbf{K})$ or the mRNAs of GAD65 $\mathbf{( F , J , L )}$ or VGLUT2 (H). The immunoreactive sites for

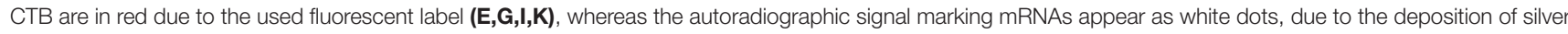
grains, were photographed at dark field illumination $(\mathbf{F}, \mathbf{H}, \mathbf{J}, \mathbf{L})$. Yellow dashed lines are used-in both single channel images to highlight the position of the retrogradely-labeled cells under the silver grains. There are two CTB-positive cells expressing GAD65 mRNA in the SPA (E,F,I,J), in contrast those in the PaV are not labeled for this marker of GABAergic neurons $\mathbf{( K , L )}$. The autoradiographic signal varies from cell to cell, as exemplified by $(\mathbf{G}, \mathbf{H})$; there are retrogradely-labeled cells showing strong autoradiographic signal for VGLUT2 mRNA in the SPa (cell number 1 and 2), a moderate signal in the PaV (cell number 3 and 4 ) and a signal, which fell below the threshold for considering as double-labeled (cell number 5). Scale bars: $200 \mu \mathrm{m}$ for (A,B), $50 \mu \mathrm{m}$ for (C,D), $25 \mu \mathrm{m}$ for (E,L).

and reward. GABAergic neurons in the peri-Pa region (Roland and Sawchenko, 1993) are activated by both acute and chronic stress conditions, and respond to these conditions with, respectively, reduced or increased GAD65 mRNA expression (Bowers et al., 1998). An indirect pathway has already been described which originates from these "extranuclear" regions of the lateral hypothalamus (e.g., the juxtaparaventricular and juxtadorsomedial parts of the lateral hypothalamus) and mediates negative reward and aversive stimuli to the VTA (Matsumoto and Hikosaka, 2007; Hikosaka et al., 2008) via 
the lateral habenula (Hahn and Swanson, 2012). Very high numbers of CTB-positive neurons appeared in the PeFLH and the surrounded PeF, which encompasses discretely and differently defined lateral hypothalamic regions, including the juxtadorsomedial and the suprafornical regions, the connections of which have been extensively studied recently (Hahn and Swanson, 2012). It will be important to investigate how the predominantly GABAergic input from the PeFLH and PeF, and the mainly glutamatergic input from the JPLH contribute to the relation and integration of motivational or incentive value associated with the ingestive or defensive behaviors, respectively.

\section{VTA-Projecting Neurons Expressing the Glutamatergic Marker, VGLUT2 or the GABAergic Marker, GAD65 mRNA}

Characterization of the transmitter phenotype of CTB-IR neurons in the hypothalamus revealed that neurons projecting to the VTA in all traced subdivisions consist of mixed glutamatergic (VGLUT2 mRNA expressing) and GABAergic (GAD65 mRNA expressing) populations. Even in hypothalamic nuclei known to express primarily VGLUT2 i.e., VMH or Pa, about one tenth of CTB-IR neurons were GAD65-positive. The proportion of glutamatergic and GABAergic neurons showed high variations within the different subdivisions. VGLUT2 mRNA signal was detected in $24-59 \%$ and GAD65 mRNA signal in $5-58 \%$ of CTB-IR neurons in the different regions and nuclei. Yet unknown subsets of the neurons projecting to the VTA secrete various peptides (Meister et al., 1988; Dallvechia-Adams et al., 2002; Hrabovszky and Liposits, 2008) that play important modulatory roles in the VTA (Korotkova et al., 2003, 2006; Geisler and Wise, 2008). Of note, GABA or glutamate may be present in certain peptidergic neurons, as it was concluded from ultrastructural data showing the presynaptic presence of small clear vesicles together with $\mathrm{CRH}$ (Tagliaferro and Morales, 2008), orexin/hypocretin (BalcitaPedicino and Sesack, 2007) or CART (Dallvechia-Adams et al., 2002) in axon terminals establishing symmetric or asymmetric synapses. The presence of the same peptide in putative GABAergic and glutamatergic terminals raises the possibility that both VGLUT2 and GAD65 mRNA expressing neurons represent phenotypically diverse cell populations, and different peptide receptor subtypes (Wang et al., 2007; Boyson et al., 2011; Hwa et al., 2013) are involved in their signaling pathways.

The glutamatergic character of the VTA-projecting neurons was examined by in situ hybridization for VGLUT2 mRNA, which is the predominant vesicular glutamate transporter isoform in the hypothalamus (Ziegler et al., 2002). VGLUT2 mRNA expression could be detected in VTA-projecting neurons of all hypothalamic regions analyzed, suggesting that the double-labeled neurons contribute significantly to the subcortical glutamatergic innervation of the VTA. The percentage of double labeled neurons varied from 20 to $60 \%$, with the highest values obtained for the $\mathrm{VMH}$, AVPO, MnPO, MPO and VOLT. The lowest percentage of VGLUT2 expression in CTB-IR neurons was observed in the SPa. The co-localization level found in the current study is higher in most subdivisions than those previously reported for the whole preoptic area $(\sim 24 \%)$ or the anterior, tuberal and mammillary regions of the hypothalamus ( 22\%; Geisler et al., 2007); this may be due to differences in the applied tracing and histological methods and/or in the rat strains used. Glutamatergic synapses in the VTA undergo plastic changes, but the LTP-like phenomenon is only temporal in response to natural rewards, such as food. This is in contrast with the persistent changes evoked by drug abuse (Chen et al., 2008). To what extent the excitatory synapses of hypothalamic origin participate in the temporal changes induced by natural reward or in more persistent changes evoked by drug abuse is not known.

We selected a probe recognizing GAD65 mRNAs for the identification of GABAergic neurons, since most classes of GABA neurons in the CNS contain mRNAs for both GAD65 and GAD67 (Esclapez et al., 1993), and both are heavily present in the same hypothalamic regions. GAD65 expression could be detected in VTA-projecting neurons of all hypothalamic regions analyzed, suggesting that, besides glutamate, GABA also contributes significantly to the transmission of hypothalamic signals to VTA neurons. While GABAergic projections from the medial preoptic area to the VTA have already been identified (Tobiansky et al., 2013), our present study is the first to report an extensive GABAergic input to the VTA from diverse hypothalamic regions. We show relatively few GABAergic cells among the VTA-projecting neurons in the male MPA $(18.26 \pm 2.14 \%)$ and the MPO (14.17 $\pm 6.64 \%)$, in comparison with the high colocalization level $(\sim 68 \%)$ reported for female rats (Tobiansky et al., 2013). Some sex differences in the anatomical (Northcutt and Nguyen, 2014) and biochemical composition (Gardner, 2005; Ceylan-Isik et al., 2010; Lee et al., 2014) and in the electrophysiological properties (Melis et al., 2013) of the mesocorticostriatal system are well known. Thus, the discrepancy in co-localization levels might be due to sexually dimorphic projections from the MPA/MPO region to the VTA. Technical issues contributing to the differences, however, should also be taken into account. The highest percentage of GAD65 mRNA expression by VTAprojecting neurons was found in some LHs i.e., the perifornical $(\sim 58 \%)$, the tuberal $(\sim 40 \%)$ and the peduncular $(\sim 30 \%)$ parts, whereas the juxtaparaventricular part was an exception with its low colocalization percentage $(\sim 10 \%)$. The tuberal lateral hypothalamic neurons have a particular importance, since this region is associated with hunger recognition; damage to this area can cause reduced food intake (Williams et al., 2000; Konturek et al., 2005). The direct GABAergic pathways from the hypothalamic regions we identified in our present study supplement the GABAergic inputs arising from the rostro-medial tegmental nucleus (the tail of the VTA), which is thought to play an integrative role collecting information from the lateral habenula related to negative reward and aversion (Barrot et al., 2012; Bourdy and Barrot, 2012). 


\section{Technical Considerations and Limitations}

The percentages of GABAergic plus glutamatergic neurons projecting to the VTA in the different anatomical regions varied between 50\% (e.g., VOLT, JPLH, SPa) to nearly $100 \%$ (Arc, PeFLH). This indicates that either a certain subset of VTA-projecting neurons does not express GAD65 or VGLUT2 mRNAs or in some cases the detection of these mRNAs fell below the sensitivity of our ISHH method. Although GAD65expressing GABAergic and VGLUT2-expressing glutamatergic neurons exhibited distribution patterns complementary to one another both in the current, as well as our previous studies (Hrabovszky et al., 2012), analyses at single cell level revealed a subset of neurons being negative for these markers scattered within the predominantly GAD65- or VGLUT2 positive subdivisions of the hypothalamus. Of note, some of the hypothalamic GABAergic and glutamatergic neurons can only be identified by GAD67 (Esclapez et al., 1993) and VGLUT1 (Ziegler et al., 2002) expression, respectively. The absence of GABAergic and glutamatergic markers from peptidergic neurons of the hypothalamus is also possible. Accordingly, single-cell PCR data of Harthoorn et al. (2005) indicate that relatively large proportions of $\mathrm{MCH}$ or orexin neurons are devoid of both GABA and glutamate. The VTA consists of different cell types, but only the dopamine neurons are thought to mediate signal discrepancies between expected and actual rewards [33]. Ultrastructural studies on TH cells in samples labeled either for neuronal tracers injected to different parts of the brain, or neuropeptides synthetized in extra-VTA neurons suggest, that $\mathrm{TH}$ neurons receive inputs from both intrinsic (Omelchenko and Sesack, 2009) and extrinsic (Dallvechia-Adams et al., 2002; Omelchenko and Sesack, 2005, 2010; Balcita-Pedicino and Sesack, 2007; Tagliaferro and Morales, 2008) sources. Since both types of axon terminals establishing either symmetric or asymmetric synapses were detected on TH-IR neurons, it is very likely, that the GABAergic and glutamatergic neurons located in different subdivisions of the hypothalamus also contribute to the innervation of dopamine neurons. The identification of additional target cells in the VTA, require further studies. For example, the hypothalamic afferents of the functionally distinct caudal end of VTA containing primarily GABAergic neurons (the rostromedial tegmental nucleus, RMTg) have not been studied here. A recent article by Yetnikoff et al. (2015) revealed the hypothalamic afferent neurons of this region, which were not significantly different in distribution or number from those of the main VTA. Phenotyping of these hypothalamic afferents is an important goal of the oncoming experiments.

\section{Functional Considerations}

The explored hypothalamic afferent systems of the VTA are thought to carry information about integrative physiological actions of the hypothalamus which ensure the proper operation and regulation of reproduction, feeding and energy expenditure, stress, adaptation, and sleep. These mechanisms maintain the homeostatic balance of the organism and are also supported by the reward system.

\section{Feeding Regulation}

Regarding the food intake, it is promoted by hunger, a homeostatic stimulus which activates the orexigenic NPY/AGRP neurons in the Arc and the orexin/hypocretin cells in the LH. Eating is terminated by satiety, which, in turn, activates the anorexigenic POMC/CART neurons in the Arc, as well as neurons of the ventromedial hypothalamic nucleus $(\mathrm{VMH}$; $\mathrm{Wu}$ et al., 2014). Neurons projecting to the VTA from the Arc and VMH are relatively sparse. In contrast, large cell populations project to the VTA from the perifornical area (PeF), the $\mathrm{LH}$ and the dorsomedial hypothalamic nucleus (DM), regions activated in association with food reward processing (Hara et al., 2001; Harris and Aston-Jones, 2006; Tsujino and Sakurai, 2009), and in animals exhibiting food anticipatory behavior (Poulin and Timofeeva, 2008; Jiménez et al., 2013). Previous studies have already revealed the peptidergic phenotype of several neurons projecting to the VTA from these areas (for recent review, see Liu and Borgland, 2015). Thus, NT-containing neurons have been shown to innervate the VTA both directly (Geisler and Zahm, 2006; Kempadoo et al., 2013) and indirectly via orexin neurons and to mediate leptin's effect for generating food reward (Leinninger et al., 2011; Opland et al., 2013). Besides contributing to the regulation of the homeostatic and hedonistic components of food intake (Hurley and Johnson, 2014; Valdivia et al., 2014), the orexin-containing neurons have been reported to play important roles in reward processing and addiction (Aston-Jones et al., 2010; Cason et al., 2010). Finally, MCH-containing neurons have also been shown to connect the homeostatic and reward systems (Sherwood et al., 2012). Of note, the primary classical neurotransmitter in orexin neurons is glutamate, whereas the $\mathrm{MCH}$ and the NT neurons use mainly GABA (Meister et al., 1989; Meister, 2007). The specific way of using the classical neurotransmitters and neuropeptides within the neuronal circuits operating during homeostatic control of energy balance vs. hedonistic food intake is far from being fully understood.

\section{Regulation of Drinking}

Drinking has been shown to increase dopamine release in the VTA, suggesting a reward value of rehydration for the animals (Yoshida et al., 1992). Both acute and chronic dehydration activate neurons in osmosensitive areas i.e., the supraoptic (SON) and paraventricular nuclei (PVN), VOLT, the MnPO and the subfornical organ (SFO). cFos activation is silenced by rehydration in each of these regions, as shown on transgenic rats expressing cFos-fluorescent reporter fusion proteins (Yoshimura et al., 2013). Dopamine release when the activity of osmosensitive areas is silenced suggests a reduced inhibitory input to VTA dopaminergic neurons from these areas. Considering that the SON and the magnocellular subdivision of the Pa contain no or very few VTA-projecting neurons, and most VTA-projecting neurons in the Pa, VOLT, and MnPO are glutamatergic, it is very likely that they terminate on VTA's local inhibitory neurons. This postulation, however, needs to be confirmed. 


\section{Stress and Adaption}

Interactions between stress and the mesocorticolimbic dopamine system have been suggested by multiple behavioral and electrophysiological studies showing stressor-induced dopamine release in the prefrontal cortex (Abercrombie et al., 1989), in the NAc shell (Kalivas et al., 1987) and in the basolateral amygdala (Inglis and Moghaddam, 1999). Glutamate is thought to be a key mediator of stressor signals in the VTA (Wang et al., 2005, 2012), the effect of which is enhanced by various neuromodulators, including $\mathrm{CRH}$ (Wise and Morales, 2010), and hypocretin/orexin (Wang et al., 2009). Consistent with the colocalization of VGLUT2 and CRH (Hrabovszky et al., 2005c) or hypocretin/orexin (Rosin et al., 2003) in subsets of paraventricular or lateral hypothalamic neurons, respectively, it is likely that the current tracing study identified relatively large numbers of VTA-projecting VGLUT2/CRH and VGLUT2/hypocretin/orexin neurons at these sites.

\section{Social Interaction}

There is abundant evidence for the rewarding feature of social interactions. Anticipation of sexual activity and mating in males and females induces cFos activation and dopamine release in the NAc (Damsma et al., 1992; Pfaus et al., 1995; Bradley and Meisel, 2001; Jenkins and Becker, 2003). Dopamine has also been implicated in the expression of maternal behaviors. Pup presentation to a lactating dam increases levels of dopamine (Hansen et al., 1993) and cFos activity (Fleming et al., 1994) in the NAc, whereas removal of dopamine fibers or pharmacological blockage of dopamine receptors in the NAc impairs maternal behaviors (Hansen, 1994; Keer and Stern, 1999). The above results strongly suggest that mesolimbic activity plays a critical role in the rewarding component of sexual and maternal behaviors. The relatively high number of neurons projecting to the VTA in preoptic and hypothalamic centers of sexual and maternal behaviors (i.e., the $\mathrm{MPO}$ and $\mathrm{VMH}$ ), raises the possibility

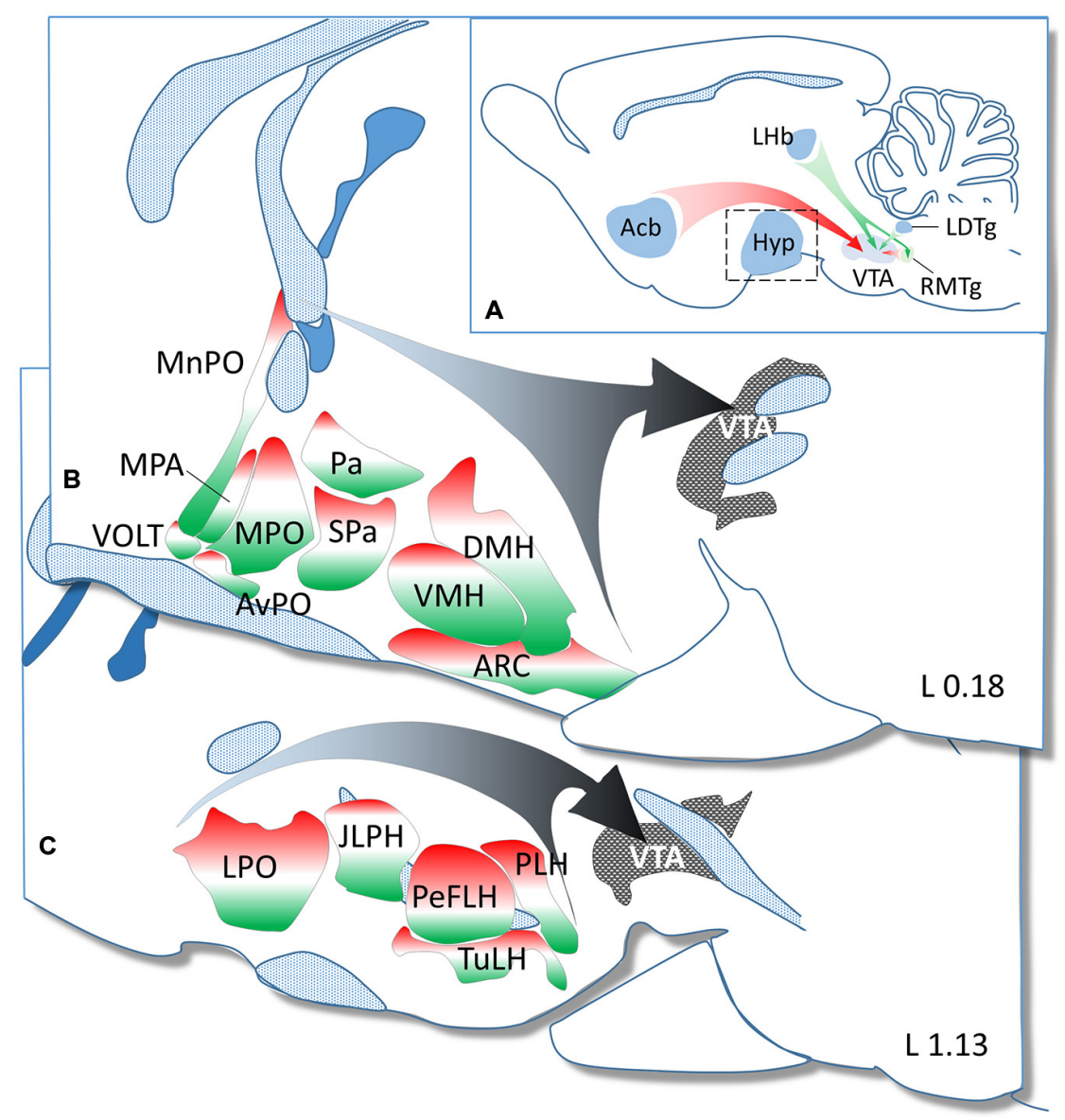

FIGURE 5 | Summary diagram to demonstrate the GABAergic and glutamatergic phenotype in neurons projecting from hypothalamic regions to the ventral tegmental area (VTA). (A) In addition to the major GABAergic (from the NAc and RMtg) and glutamatergic (from the LHb and LDtg) inputs, the hypothalamus (enframed) also represents a significant source of GABAergic and glutamatergic afferents to the VTA. The hypothalamic nuclei and regions demonstrated in two paramedian sagittal sections $(\mathbf{B}=\mathrm{L} 0.18$ and $\mathbf{C}=\mathrm{L} 1.13 \mathrm{~mm}$ ) are color-coded to illustrate the relative ratio of GAD65 (red) and VGLUT2 (green) expressing neurons. The white color shows the relative ratio of neurons, which either do not express these markers or express them below the detection threshold of ISHH. 
that these nuclei are the source of reward signals in this context.

It is well known that aggressive/dominance behavior induces cFos activation in the VTA (Smith et al., 1997; Miczek et al., 2011; Gil et al., 2013; Wang et al., 2013), as well as in the hypothalamic attack area involving the lateroanterior hypothalamic and the anterior hypothalamic nuclei, the retrochiasmatic area, the ventrolateral part of the $\mathrm{VMH}$, and the tuber cinereum area (dorsolateral to the ventromedial nucleus; Hrabovszky et al., 2005a). This area appears to be different from brain structures involved in defense against predators, which consists of the anterior hypothalamic nucleus, dorsomedial part of the $\mathrm{VMH}$, and the dorsal premammillary nucleus (Motta et al., 2009), brain regions which are highly interconnected (Thompson and Swanson, 2010). Most of these areas contain only a few VTAprojecting neurons, with the exception of the tuberal part of the lateral hypothalamus, which was well-populated by a mixture of GABAergic and glutamatergic neurons in our present study.

In conclusion, results of our present study provide detailed information about medial and lateral hypothalamic regions that provide neuronal input to the VTA. Among these cells, the proportion of glutamatergic and GABAergic neurons showed regional variation (Figure 5), with a predominance of glutamatergic neurons in most hypothalamic nuclei

\section{References}

Abercrombie, E. D., Keefe, K. A., DiFrischia, D. S., and Zigmond, M. J. (1989). Differential effect of stress on in vivo dopamine release in striatum, nucleus accumbens and medial frontal cortex. J. Neurochem. 52, 1655-1658. doi: 10. 1111/j.1471-4159.1989.tb09224.x

Adams, J. C. (1992). Biotin amplification of biotin and horseradish peroxidase signals in histochemical stains. J. Histochem. Cytochem. 40, 1457-1463. doi: 10. $1177 / 40.10 .1527370$

Arias-Carrión, O., Stamelou, M., Murillo-Rodríguez, E., Menéndez-González, M., and Pöppel, E. (2010). Dopaminergic reward system: a short integrative review. Int. Arch. Med. 3:24. doi: 10.1186/1755-7682-3-24

Aston-Jones, G., Smith, R. J., Sartor, G. C., Moorman, D. E., Massi, L., TahsiliFahadan, P., et al. (2010). Lateral hypothalamic orexin/hypocretin neurons: a role in reward-seeking and addiction. Brain Res. 1314, 74-90. doi: 10.1016/j. brainres.2009.09.106

Balcita-Pedicino, J. J., and Sesack, S. R. (2007). Orexin axons in the rat ventral tegmental area synapse infrequently onto dopamine and gammaaminobutyric acid neurons. J. Comp. Neurol. 503, 668-684. doi: 10.1002/cne. 21420

Balthazart, J., and Ball, G. F. (2007). Topography in the preoptic region: differential regulation of appetitive and consummatory male sexual behaviors. Front. Neuroendocrinol. 28:161-178. doi: 10.1016/j.yfrne.2007.05.003

Barrot, M., Sesack, S. R., Georges, F., Pistis, M., Hong, S., and Jhou, T. C. (2012). Braking dopamine systems: a new GABA master structure for mesolimbic and nigrostriatal functions. J. Neurosci. 32, 14094-14101. doi: 10.1523/jneurosci. 3370-12.2012

Bourdy, R., and Barrot, M. (2012). A new control center for dopaminergic systems: pulling the VTA by the tail. Trends Neurosci. 35, 681-690. doi: 10.1016/j.tins. 2012.06.007

Bowers, G., Cullinan, W. E., and Herman, J. P. (1998). Region-specific regulation of glutamic acid decarboxylase (GAD) mRNA expression in central stress circuits. J. Neurosci. 18, 5938-5947.

Boyson, C. O., Miguel, T. T., Quadros, I. M., Debold, J. F., and Miczek, K. A. (2011). Prevention of social stress-escalated cocaine self-administration by CRF-R1 antagonist in the rat VTA. Psychopharmacology (Berl) 218, 257-269. doi: $10.1007 /$ s00213-011-2266-8 including the $\mathrm{VMH}, \mathrm{MnPO}$ or $\mathrm{Pa}$, and GABAergic neurons in lateral hypothalamic subdivisions involving the PeFLH and TuLH. In addition, neurons, which fail to express the GABAergic and glutamatergic markers or expressing them at low levels are also numerous in most hypothalamic regions. This suggests, that neurons using other neurotransmitters and/or neuropeptides may also contribute significantly to the hypothalamic innervation of the VTA.

\section{Acknowledgments}

Support contributed by grants from the National Science Foundation of Hungary (OTKA K101326, K100722, K83710, K112669), the "Lendület" program of the Hungarian Academy of Sciences and the National Brain Research Program. The research leading to these results has received funding from the European Community's Seventh Framework Programme (FP7/2007-2013) under Grant Agreement 245009 and the National Development Agency (BONUS HU 08/2-2011-0006). The authors wish to thank Barna László and Hajnalka Bekó for their excellent technical assistance. The atlas figures modified in Figure 1 were originally published in The Rat Brain in Stereotaxic Coordinates: The New Coronal Set. Fifth edition, George Paxinos and Charles Watson, Copyright Elsevier (2005).

Bradley, K. C., and Meisel, R. L. (2001). Sexual behavior induction of c-Fos in the nucleus accumbens and amphetamine-stimulated locomotor activity are sensitized by previous sexual experience in female Syrian hamsters. J. Neurosci. 21, 2123-2130.

Cason, A. M., Smith, R. J., Tahsili-Fahadan, P., Moorman, D. E., Sartor, G. C., and Aston-Jones, G. (2010). Role of orexin/hypocretin in reward-seeking and addiction: implications for obesity. Physiol. Behav. 100, 419-428. doi: 10.1016/j. physbeh.2010.03.009

Ceylan-Isik, A. F., McBride, S. M., and Ren, J. (2010). Sex difference in alcoholism: who is at areater risk for development of alcoholic complication? Life Sci. 87, 133-138. doi: 10.1016/j.lfs.2010.06.002

Champagne, D., Beaulieu, J., and Drolet, G. (1998). CRFergic innervation of the paraventricular nucleus of the rat hypothalamus: a tract-tracing study. J. Neuroendocrinol. 10, 119-131. doi: 10.1046/j.1365-2826.1998. 00179.x

Chen, B. T., Bowers, M. S., Martin, M., Hopf, F. W., Guillory, A. M., Carelli, R. M., et al. (2008). Cocaine but not natural reward self-administration nor passive cocaine infusion produces persistent LTP in the VTA. Neuron 59, 288-297. doi: 10.1016/j.neuron.2008.05.024

Chen, P., Li, C., Haskell-Luevano, C., Cone, R. D., and Smith, M. S. (1999). Altered expression of agouti-related protein and its colocalization with neuropeptide $\mathrm{Y}$ in the arcuate nucleus of the hypothalamus during lactation. Endocrinology 140 , 2645-2650. doi: 10.1210/en.140.6.2645

Dallvechia-Adams, S., Kuhar, M. J., and Smith, Y. (2002). Cocaine- and amphetamine-regulated transcript peptide projections in the ventral midbrain: colocalization with gamma-aminobutyric acid, melanin-concentrating hormone, dynorphin and synaptic interactions with dopamine neurons. J. Comp. Neurol. 448, 360-372. doi: 10.1002/cne.10268

Damsma, G., Pfaus, J. G., Wenkstern, D., Phillips, A. G., and Fibiger, H. C. (1992). Sexual behavior increases dopamine transmission in the nucleus accumbens and striatum of male rats: comparison with novelty and locomotion. Behav. Neurosci. 106, 181-191. doi: 10.1037/0735-7044.106. 1.181

Dietrich, M. O., Bober, J., Ferreira, J. G., Tellez, L. A., Mineur, Y. S., Souza, D. O., et al. (2012). AgRP neurons regulate development of dopamine neuronal plasticity and nonfood-associated behaviors. Nat. Neurosci. 15, 1108-1110. doi: $10.1038 /$ nn.3147 
Di Sebastiano, A. R., and Coolen, L. M. (2012). Orexin and natural reward: feeding, maternal and male sexual behavior. Prog. Brain Res. 198, 65-77. doi: 10. 1016/B978-0-444-59489-1.00006-9

Ericson, H., Blomqvist, A., and Köhler, C. (1991). Origin of neuronal inputs to the region of the tuberomammillary nucleus of the rat brain. J. Comp. Neurol. 311, 45-64. doi: 10.1002/cne.903110105

Esclapez, M., Tillakaratne, N. J., Tobin, A. J., and Houser, C. R. (1993). Comparative localization of mRNAs encoding two forms of glutamic acid decarboxylase with nonradioactive in situ hybridization methods. J. Comp. Neurol. 331, 339-362. doi: 10.1002/cne.903310305

Fields, H. L., Hjelmstad, G. O., Margolis, E. B., and Nicola, S. M. (2007). Ventral tegmental area neurons in learned appetitive behavior and positive reinforcement. Annu. Rev. Neurosci. 30, 289-316. doi: 10.1146/annurev.neuro. 30.051606 .094341

Finley, J. C., Lindström, P., and Petrusz, P. (1981). Immunocytochemical localization of beta-endorphin-containing neurons in the rat brain. Neuroendocrinology 33, 28-42. doi: 10.1159/000123197

Fleming, A. S., Suh, E. J., Korsmit, M., and Rusak, B. (1994). Activation of Foslike immunoreactivity in the medial preoptic area and limbic structures by maternal and social interactions in rats. Behav. Neurosci. 108, 724-734. doi: 10. 1037/0735-7044.108.4.724

Gardner, E. L. (2005). Endocannabinoid signaling system and brain reward: emphasis on dopamine. Pharmacol. Biochem. Behav. 81, 263-284. doi: 10. 1016/j.pbb.2005.01.032

Geisler, S., Derst, C., Veh, R. W., and Zahm, D. S. (2007). Glutamatergic afferents of the ventral tegmental area in the rat. J. Neurosci. 27, 5730-5743. doi: 10. 3410/f.1086807.539731

Geisler, S., and Wise, R. A. (2008). Functional implications of glutamatergic projections to the ventral tegmental area. Rev. Neurosci. 19, 227-244. doi: 10 . 1515/revneuro.2008.19.4-5.227

Geisler, S., and Zahm, D. S. (2005). Afferents of the ventral tegmental area in the rat-anatomical substratum for integrative functions. J. Comp. Neurol. 490, 270-294. doi: 10.1002/cne.20668

Geisler, S., and Zahm, D. S. (2006). Neurotensin afferents of the ventral tegmental area in the rat: [1] re-examination of their origins and [2] responses to acute psychostimulant and antipsychotic drug administration. Eur. J. Neurosci. 24, 116-134. doi: 10.1111/j.1460-9568.2006.04928.x

Gil, M., Nguyen, N. T., McDonald, M., and Albers, H. E. (2013). Social reward: interactions with social status, social communication, aggression and associated neural activation in the ventral tegmental area. Eur. J. Neurosci. 38, 2308-2318. doi: 10.1111/ejn.12216

Hahn, J. D., and Swanson, L. W. (2010). Distinct patterns of neuronal inputs and outputs of the juxtaparaventricular and suprafornical regions of the lateral hypothalamic area in the male rat. Brain Res. Rev. 64, 14-103. doi: 10.1016/j. brainresrev.2010.02.002

Hahn, J. D., and Swanson, L. W. (2012). Connections of the lateral hypothalamic area juxtadorsomedial region in the male rat. J. Comp. Neurol. 520, 1831-1890. doi: $10.1002 /$ cne.23064

Hansen, S. (1994). Maternal behavior of female rats with 6-OHDA lesions in the ventral striatum: characterization of the pup retrieval deficit. Physiol. Behav. 55, 615-620. doi: 10.1016/0031-9384(94)90034-5

Hansen, S., Bergvall, A. H., and Nyiredi, S. (1993). Interaction with pups enhances dopamine release in the ventral striatum of maternal rats: a microdialysis study. Pharmacol. Biochem. Behav. 45, 673-676. doi: 10.1016/0091-3057(93)90523-v

Hara, R., Wan, K., Wakamatsu, H., Aida, R., Moriya, T., Akiyama, M., et al. (2001). Restricted feeding entrains liver clock without participation of the suprachiasmatic nucleus. Genes Cells 6, 269-278. doi: 10.1046/j.1365-2443. 2001.00419.x

Harris, G. C., and Aston-Jones, G. (2006). Arousal and reward: a dichotomy in orexin function. Trends Neurosci. 29, 571-577. doi: 10.1016/j.tins.2006.08.002

Harthoorn, L. F., Sañé, A., Nethe, M., and Van Heerikhuize, J. J. (2005). Multi-transcriptional profiling of melanin-concentrating hormone and orexincontaining neurons. Cell. Mol. Neurobiol. 25, 1209-1223. doi: 10.1007/s10571005-8184-8

Hays, L. E., Carpenter, C. D., and Petersen, S. L. (2002). Evidence that GABAergic neurons in the preoptic area of the rat brain are targets of 2,3,7,8tetrachlorodibenzo-p-dioxin during development. Environ. Health Perspect. 110(Suppl. 3), 369-376. doi: 10.1289/ehp.02110s3369
Hikosaka, O., Bromberg-Martin, E., Hong, S., and Matsumoto, M. (2008). New insights on the subcortical representation of reward. Curr. Opin. Neurobiol. 18, 203-208. doi: 10.1016/j.conb.2008.07.002

Holstege, G. (1987). Some anatomical observations on the projections from the hypothalamus to brainstem and spinal cord: an HRP and autoradiographic tracing study in the cat. J. Comp. Neurol. 260, 98-126. doi: 10.1002/cne. 902600109

Hrabovszky, E., Halász, J., Meelis, W., Kruk, M. R., Liposits, Z., and Haller, J. (2005a). Neurochemical characterization of hypothalamic neurons involved in attack behavior: glutamatergic dominance and co-expression of thyrotropinreleasing hormone in a subset of glutamatergic neurons. Neuroscience 133, 657-666. doi: 10.1016/j.neuroscience.2005.03.042

Hrabovszky, E., Kalló, I., Steinhauser, A., Merchenthaler, I., Coen, C. W., Petersen, S. L., et al. (2004a). Estrogen receptor-beta in oxytocin and vasopressin neurons of the rat and human hypothalamus: immunocytochemical and in situ hybridization studies. J. Comp. Neurol. 473, 315-333. doi: 10.1002/cne. 20127

Hrabovszky, E., and Liposits, Z. (2008). Novel aspects of glutamatergic signaling in the neuroendocrine system. J. Neuroendocrinol. 20, 743-751. doi: 10.1111/j. 1365-2826.2008.01719.x

Hrabovszky, E., and Petersen, S. L. (2002). Increased concentrations of radioisotopically-labeled complementary ribonucleic acid probe, dextran sulfate and dithiothreitol in the hybridization buffer can improve results of in situ hybridization histochemistry. J. Histochem. Cytochem. 50, 1389-1400. doi: 10.1177/002215540205001012

Hrabovszky, E., Turi, G. F., Kalló, I., and Liposits, Z. (2004b). Expression of vesicular glutamate transporter-2 in gonadotropin-releasing hormone neurons of the adult male rat. Endocrinology 145, 4018-4021. doi: 10.1210/en.2004-0589

Hrabovszky, E., Turi, G. F., and Liposits, Z. (2005b). Presence of vesicular glutamate transporter-2 in hypophysiotropic somatostatin but not growth hormone-releasing hormone neurons of the male rat. Eur. J. Neurosci. 21, 2120-2126. doi: 10.1111/j.1460-9568.2005.04076.x

Hrabovszky, E., Wittmann, G., Kalló, I., Füzesi, T., Fekete, C., and Liposits, Z. (2012). Distribution of type 1 cannabinoid receptor-expressing neurons in the septal-hypothalamic region of the mouse: colocalization with GABAergic and glutamatergic markers. J. Comp. Neurol. 520, 1005-1020. doi: 10.1002/cne. 22766

Hrabovszky, E., Wittmann, G., Turi, G. F., Liposits, Z., and Fekete, C. (2005c). Hypophysiotropic thyrotropin-releasing hormone and corticotropin-releasing hormone neurons of the rat contain vesicular glutamate transporter-2. Endocrinology 146, 341-347. doi: 10.1210/en.2004-0856

Hurley, S. W., and Johnson, A. K. (2014). The role of the lateral hypothalamus and orexin in ingestive behavior: a model for the translation of past experience and sensed deficits into motivated behaviors. Front. Syst. Neurosci. 8:216. doi: 10. 3389/fnsys.2014.00216

Hwa, L. S., Debold, J. F., and Miczek, K. A. (2013). Alcohol in excess: CRF(1) receptors in the rat and mouse VTA and DRN. Psychopharmacology (Berl) 225, 313-327. doi: 10.1007/s00213-012-2820-Z

Inglis, F. M., and Moghaddam, B. (1999). Dopaminergic innervation of the amygdala is highly responsive to stress. J. Neurochem. 72, 1088-1094. doi: 10. 1046/j.1471-4159.1999.0721088.x

Jenkins, W. J., and Becker, J. B. (2003). Dynamic increases in dopamine during paced copulation in the female rat. Eur. J. Neurosci. 18, 1997-2001. doi: 10. 1046/j.1460-9568.2003.02923.x

Jiménez, A., Caba, M., and Escobar, C. (2013). Food-entrained patterns in orexin cells reveal subregion differential activation. Brain Res. 1513, 41-50. doi: 10. 1016/j.brainres.2013.03.031

Kalivas, P. W., Duffy, P., and Latimer, L. G. (1987). Neurochemical and behavioral effects of corticotropin-releasing factor in the ventral tegmental area of the rat. J. Pharmacol. Exp. Ther. 242, 757-763.

Keer, S. E., and Stern, J. M. (1999). Dopamine receptor blockade in the nucleus accumbens inhibits maternal retrieval and licking, but enhances nursing behavior in lactating rats. Physiol. Behav. 67, 659-669. doi: 10.1016/s00319384(99)00116-x

Kempadoo, K. A., Tourino, C., Cho, S. L., Magnani, F., Leinninger, G. M., Stuber, G. D., et al. (2013). Hypothalamic neurotensin projections promote reward by enhancing glutamate transmission in the VTA. J. Neurosci. 33, 7618-7626. doi: 10.1523/JNEUROSCI.2588-12.2013 
Kerstens, H. M., Poddighe, P. J., and Hanselaar, A. G. (1995). A novel in situ hybridization signal amplification method based on the deposition of biotinylated tyramine. J. Histochem. Cytochem. 43, 347-352. doi: 10.1177/43. 4.7897179

Konturek, P. C., Konturek, J. W., Cze śnikiewicz-Guzik, M., Brzozowski, T., Sito, E., and Konturek, S. J. (2005). Neuro-hormonal control of food intake: basic mechanisms and clinical implications. J. Physiol. Pharmacol. 56(Suppl. 6), 5-25.

Korotkova, T. M., Brown, R. E., Sergeeva, O. A., Ponomarenko, A. A., and Haas, H. L. (2006). Effects of arousal- and feeding-related neuropeptides on dopaminergic and GABAergic neurons in the ventral tegmental area of the rat. Eur. J. Neurosci. 23, 2677-2685. doi: 10.1111/j.1460-9568.2006.04792.x

Korotkova, T. M., Sergeeva, O. A., Eriksson, K. S., Haas, H. L., and Brown, R. E. (2003). Excitation of ventral tegmental area dopaminergic and nondopaminergic neurons by orexins/hypocretins. J. Neurosci. 23, 7-11.

Lee, T. T., Wainwright, S. R., Hill, M. N., Galea, L. A., and Gorzalka, B. B. (2014). Sex, drugs and adult neurogenesis: sex-dependent effects of escalating adolescent cannabinoid exposure on adult hippocampal neurogenesis, stress reactivity and amphetamine sensitization. Hippocampus 24, 280-292. doi: 10 . 1002/hipo.22221

Leinninger, G. M., Opland, D. M., Jo, Y. H., Faouzi, M., Christensen, L., Cappellucci, L. A., et al. (2011). Leptin action via neurotensin neurons controls orexin, the mesolimbic dopamine system and energy balance. Cell Metab. 14, 313-323. doi: 10.1016/j.cmet.2011.06.016

Liu, S., and Borgland, S. L. (2015). Regulation of the mesolimbic dopamine circuit by feeding peptides. Neuroscience 289, 19-42. doi: 10.1016/j.neuroscience.2014. 12.046

Lobb, C. J., Troyer, T. W., Wilson, C. J., and Paladini, C. A. (2011). Disinhibition bursting of dopaminergic neurons. Front. Syst. Neurosci. 5:25. doi: 10. 3389/fnsys.2011.00025

Matsumoto, M., and Hikosaka, O. (2007). Lateral habenula as a source of negative reward signals in dopamine neurons. Nature 447, 1111-1115. doi: 10. $1038 /$ nature 05860

Meister, B. (2007). Neurotransmitters in key neurons of the hypothalamus that regulate feeding behavior and body weight. Physiol. Behav. 92, 263-271. doi: 10. 1016/j.physbeh.2007.05.021

Meister, B., Ceccatelli, S., Hökfelt, T., Andén, N. E., Andén, M., and Theodorsson, E. (1989). Neurotransmitters, neuropeptides and binding sites in the rat mediobasal hypothalamus: effects of monosodium glutamate (MSG) lesions. Exp. Brain Res. 76, 343-368. doi: 10.1007/bf00247894

Meister, B., Hökfelt, T., Geffard, M., and Oertel, W. (1988). Glutamic acid decarboxylase- and gamma-aminobutyric acid-like immunoreactivities in corticotropin-releasing factor-containing parvocellular neurons of the hypothalamic paraventricular nucleus. Neuroendocrinology 48, 516-526. doi: $10.1159 / 000125058$

Melis, M., De Felice, M., Lecca, S., Fattore, L., and Pistis, M. (2013). Sex-specific tonic 2-arachidonoylglycerol signaling at inhibitory inputs onto dopamine neurons of lister hooded rats. Front. Integr. Neurosci. 7:93. doi: 10.3389/fnint. 2013.00093

Miczek, K. A., Nikulina, E. M., Takahashi, A., Covington, H. E. III, Yap, J. J., Boyson, C. O., et al. (2011). Gene expression in aminergic and peptidergic cells during aggression and defeat: relevance to violence, depression and drug abuse. Behav. Genet. 41, 787-802. doi: 10.1007/s10519-011-9462-5

Morikawa, H., and Paladini, C. A. (2011). Dynamic regulation of midbrain dopamine neuron activity: intrinsic, synaptic and plasticity mechanisms. Neuroscience 198, 95-111. doi: 10.1016/j.neuroscience.2011.08.023

Motta, S. C., Goto, M., Gouveia, F. V., Baldo, M. V., Canteras, N. S., and Swanson, L. W. (2009). Dissecting the brain's fear system reveals the hypothalamus is critical for responding in subordinate conspecific intruders. Proc. Natl. Acad. Sci. U S A 106, 4870-4875. doi: 10.1073/pnas.0900939106

Northcutt, K. V., and Nguyen, J. M. (2014). Female juvenile play elicits Fos expression in dopaminergic neurons of the VTA. Behav. Neurosci. 128, 178-186. doi: 10.1037/a0035964

Oades, R. D., and Halliday, G. M. (1987). Ventral tegmental (A10) system: neurobiology. 1. Anatomy and connectivity. Brain Res. 434, 117-165. doi: 10. 1016/0165-0173(87)90011-7

Omelchenko, N., and Sesack, S. R. (2005). Laterodorsal tegmental projections to identified cell populations in the rat ventral tegmental area. J. Comp. Neurol. 483, 217-235. doi: 10.1002/cne.20417
Omelchenko, N., and Sesack, S. R. (2009). Ultrastructural analysis of local collaterals of rat ventral tegmental area neurons: GABA phenotype and synapses onto dopamine and GABA cells. Synapse 63, 895-906. doi: 10. 1002/syn. 20668

Omelchenko, N., and Sesack, S. R. (2010). Periaqueductal gray afferents synapse onto dopamine and GABA neurons in the rat ventral tegmental area. $J$. Neurosci. Res. 88, 981-991. doi: 10.1002/jnr.22265

Opland, D., Sutton, A., Woodworth, H., Brown, J., Bugescu, R., Garcia, A., et al. (2013). Loss of neurotensin receptor-1 disrupts the control of the mesolimbic dopamine system by leptin and promotes hedonic feeding and obesity. Mol. Metab. 2, 423-434. doi: 10.1016/j.molmet.2013.07.008

Park, T. H., and Carr, K. D. (1998). Neuroanatomical patterns of fos-like immunoreactivity induced by a palatable meal and meal-paired environment in saline- and naltrexone-treated rats. Brain Res. 805, 169-180. doi: 10. 1016/s0006-8993(98)00719-7

Paxinos, G., and Watson, C. (2005). The Rat Brain in Stereotaxic Coordinates: The New Coronal Set. San Diego: Elsevier Academic Press.

Pfaus, J. G., Damsma, G., Wenkstern, D., and Fibiger, H. C. (1995). Sexual activity increases dopamine transmission in the nucleus accumbens and striatum of female rats. Brain Res. 693, 21-30. doi: 10.1016/0006-8993(95) 00679-k

Phillipson, O. T. (1979). Afferent projections to the ventral tegmental area of Tsai and interfascicular nucleus: a horseradish peroxidase study in the rat. J. Comp. Neurol. 187, 117-143. doi: 10.1002/cne.901870108

Poulin, A. M., and Timofeeva, E. (2008). The dynamics of neuronal activation during food anticipation and feeding in the brain of food-entrained rats. Brain Res. 1227, 128-141. doi: 10.1016/j.brainres.2008.06.039

Rodaros, D., Caruana, D. A., Amir, S., and Stewart, J. (2007). Corticotropinreleasing factor projections from limbic forebrain and paraventricular nucleus of the hypothalamus to the region of the ventral tegmental area. Neuroscience 150, 8-13. doi: 10.1016/j.neuroscience.2007.09.043

Roland, B. L., and Sawchenko, P. E. (1993). Local origins of some GABAergic projections to the paraventricular and supraoptic nuclei of the hypothalamus in the rat. J. Comp. Neurol. 332, 123-143. doi: 10.1002/cne.903320109

Rosin, D. L., Weston, M. C., Sevigny, C. P., Stornetta, R. L., and Guyenet, P. G. (2003). Hypothalamic orexin (hypocretin) neurons express vesicular glutamate transporters VGLUT1 or VGLUT2. J. Comp. Neurol. 465, 593-603. doi: 10. 1002/cne. 10860

Sherwood, A., Wosiski-Kuhn, M., Nguyen, T., Holland, P. C., Lakaye, B., Adamantidis, A., et al. (2012). The role of melanin-concentrating hormone in conditioned reward learning. Eur. J. Neurosci. 36, 3126-3133. doi: 10.1111/j. 1460-9568.2012.08207.x

Smith, W. J., Stewart, J., and Pfaus, J. G. (1997). Tail pinch induces fos immunoreactivity within several regions of the male rat brain: effects of age. Physiol. Behav. 61, 717-723. doi: 10.1016/s0031-9384(96)00524-0

Swanson, L. W. (1982). The projections of the ventral tegmental area and adjacent regions: a combined fluorescent retrograde tracer and immunofluorescence study in the rat. Brain Res. Bull. 9, 321-353. doi: 10.1016/0361-9230(82)90145-9

Swanson, L. W., Kucharczyk, J., and Mogenson, G. J. (1978). Autoradiographic evidence for pathways from the medial preoptic area to the midbrain involved in the drinking response to angiotensin II. J. Comp. Neurol. 178, 645-659. doi: $10.1002 /$ cne. 901780404

Tagliaferro, P., and Morales, M. (2008). Synapses between corticotropin-releasing factor-containing axon terminals and dopaminergic neurons in the ventral tegmental area are predominantly glutamatergic. J. Comp. Neurol. 506, 616-626. doi: 10.1002/cne.21576

Thompson, R. H., and Swanson, L. W. (2010). Hypothesis-driven structural connectivity analysis supports network over hierarchical model of brain architecture. Proc. Natl. Acad. Sci. U S A 107, 15235-15239. doi: 10.1073/pnas. 1009112107

Tobiansky, D. J., Roma, P. G., Hattori, T., Will, R. G., Nutsch, V. L., and Dominguez, J. M. (2013). The medial preoptic area modulates cocaine-induced activity in female rats. Behav. Neurosci. 127, 293-302. doi: 10.1037/a0031949

Tsujino, N., and Sakurai, T. (2009). Orexin/hypocretin: a neuropeptide at the interface of sleep, energy homeostasis and reward system. Pharmacol. Rev. 61, 162-176. doi: 10.1124/pr.109.001321

Tzschentke, T. M., and Schmidt, W. J. (2000). Functional relationship among medial prefrontal cortex, nucleus accumbens and ventral tegmental area 
in locomotion and reward. Crit. Rev. Neurobiol. 14, 131-142. doi: 10. 1615/critrevneurobiol.v14.i2.20

Valdivia, S., Patrone, A., Reynaldo, M., and Perello, M. (2014). Acute high fat diet consumption activates the mesolimbic circuit and requires orexin signaling in a mouse model. PLoS One 9:e87478. doi: 10.1371/journal.pone.0087478

Veening, J. G., Coolen, L. M., de Jong, T. R., Joosten, H. W., de Boer, S. F., Koolhaas, J. M., et al. (2005). Do similar neural systems subserve aggressive and sexual behavior in male rats? Insights from c-Fos and pharmacological studies. Eur. J. Pharmacol. 526, 226-239. doi: 10.1016/j.ejphar.2005. 09.041

Verhagen, L. A., Luijendijk, M. C., de Groot, J. W., van Dommelen, L. P., Klimstra, A. G., Adan, R. A., et al. (2011). Anticipation of meals during restricted feeding increases activity in the hypothalamus in rats. Eur. J. Neurosci. 34, 1485-1491. doi: 10.1111/j.1460-9568.2011.07880.x

Wang, J., Fanous, S., Terwilliger, E. F., Bass, C. E., Hammer, R. P. Jr., and Nikulina, E. M. (2013). BDNF overexpression in the ventral tegmental area prolongs social defeat stress-induced cross-sensitization to amphetamine and increases DeltaFosB expression in mesocorticolimbic regions of rats. Neuropsychopharmacology 38, 2286-2296. doi: 10.1038/npp. 2013.130

Wang, B., Shaham, Y., Zitzman, D., Azari, S., Wise, R. A., and You, Z. B. (2005). Cocaine experience establishes control of midbrain glutamate and dopamine by corticotropin-releasing factor: a role in stress-induced relapse to drug seeking. J. Neurosci. 25, 5389-5396. doi: 10.1523/jneurosci.0955-05.2005

Wang, B., You, Z. B., Rice, K. C., and Wise, R. A. (2007). Stress-induced relapse to cocaine seeking: roles for the $\mathrm{CRF}(2)$ receptor and CRF-binding protein in the ventral tegmental area of the rat. Psychopharmacology (Berl) 193, 283-294. doi: 10.1007/s00213-007-0782-3

Wang, B., You, Z. B., and Wise, R. A. (2009). Reinstatement of cocaine seeking by hypocretin (orexin) in the ventral tegmental area: independence from the local corticotropin-releasing factor network. Biol. Psychiatry 65, 857-862. doi: 10. 1016/j.biopsych.2009.01.018

Wang, B., You, Z. B., and Wise, R. A. (2012). Heroin self-administration experience establishes control of ventral tegmental glutamate release by stress and environmental stimuli. Neuropsychopharmacology 37, 2863-2869. doi: 10. 1038/npp.2012.167

Watabe-Uchida, M., Zhu, L., Ogawa, S. K., Vamanrao, A., and Uchida, N. (2012). Whole-brain mapping of direct inputs to midbrain dopamine neurons. Neuron 74, 858-873. doi: 10.1016/j.neuron.2012.03.017
Williams, G., Harrold, J. A., and Cutler, D. J. (2000). The hypothalamus and the regulation of energy homeostasis: lifting the lid on a black box. Proc. Nutr. Soc. 59, 385-396. doi: 10.1017/s0029665100000434

Wise, R. A., and Morales, M. (2010). A ventral tegmental CRF-glutamatedopamine interaction in addiction. Brain Res. 1314, 38-43. doi: 10.1016/j. brainres.2009.09.101

Wu, Q., Lemus, M. B., Stark, R., Bayliss, J. A., Reichenbach, A., Lockie, S. H., et al. (2014). The temporal pattern of cfos activation in hypothalamic, cortical and brainstem nuclei in response to fasting and refeeding in male mice. Endocrinology 155, 840-853. doi: 10.1210/en.2013-1831

Yetnikoff, L., Cheng, A. Y., Lavezzi, H. N., Parsley, K. P., and Zahm, D. S. (2015). Sources of input to the rostromedial tegmental nucleus, ventral tegmental area and lateral habenula compared: a study in rat. J. Comp. Neurol. doi: 10. 1002/cne.23797 [Epub ahead of print].

Yoshida, M., Yokoo, H., Mizoguchi, K., Kawahara, H., Tsuda, A., Nishikawa, T., et al. (1992). Eating and drinking cause increased dopamine release in the nucleus accumbens and ventral tegmental area in the rat: measurement by in vivo microdialysis. Neurosci. Lett. 139, 73-76. doi: 10.1016/03043940(92)90861-z

Yoshimura, M., Ohkubo, J., Katoh, A., Ohno, M., Ishikura, T., Kakuma, T., et al. (2013). A c-fos-monomeric red fluorescent protein 1 fusion transgene is differentially expressed in rat forebrain and brainstem after chronic dehydration and rehydration. J. Neuroendocrinol. 25, 478-487. doi: 10. 1111/jne.12022

Ziegler, D. R., Cullinan, W. E., and Herman, J. P. (2002). Distribution of vesicular glutamate transporter mRNA in rat hypothalamus. J. Comp. Neurol. 448, 217-229. doi: 10.1002/cne.10257

Conflict of Interest Statement: The authors declare that the research was conducted in the absence of any commercial or financial relationships that could be construed as a potential conflict of interest.

Copyright (c) 2015 Kalló, Molnár, Szöke, Fekete, Hrabovszky and Liposits. This is an open-access article distributed under the terms of the Creative Commons Attribution License (CC BY). The use, distribution and reproduction in other forums is permitted, provided the original author(s) or licensor are credited and that the original publication in this journal is cited, in accordance with accepted academic practice. No use, distribution or reproduction is permitted which does not comply with these terms. 